\title{
Techniques for extraction and isolation of natural products: a comprehensive review
}

\author{
Qing-Wen Zhang ${ }^{1 *} \mathbb{D}$, Li-Gen Lin ${ }^{1}$ and Wen-Cai Ye ${ }^{2^{*}}$
}

\begin{abstract}
Natural medicines were the only option for the prevention and treatment of human diseases for thousands of years. Natural products are important sources for drug development. The amounts of bioactive natural products in natural medicines are always fairly low. Today, it is very crucial to develop effective and selective methods for the extraction and isolation of those bioactive natural products. This paper intends to provide a comprehensive view of a variety of methods used in the extraction and isolation of natural products. This paper also presents the advantage, disadvantage and practical examples of conventional and modern techniques involved in natural products research.
\end{abstract}

Keywords: Natural products, Extraction, Isolation, Natural medicine, Chromatography, Phytochemical investigation

\section{Background}

Natural medicines, such as traditional Chinese medicine (TCM) and Ayurveda, were formed and developed in the daily life of ancient people and in the process of their fight against diseases over thousands of years, and they have produced a positive impact on the progress of human civilization. Today, natural medicines not only provide the primary health-care needs for the majority of the population in developing countries but have attracted more and more attention in developed countries due to soaring health-care costs and universal financial austerity. In the USA, approximately $49 \%$ of the population has tried natural medicines for the prevention and treatment of diseases [1]. Chemicals known to have medicinal benefits are considered to be "active ingredients" or "active principles" of natural medicines. Natural products have provided the primary sources for new drug development. From the 1940s to the end of 2014, nearly half of the FDA approved chemical drugs for the treatment of human diseases were derived from or inspired by natural products

\footnotetext{
*Correspondence: qwzhang@umac.mo; chywc@aliyun.com

${ }^{1}$ State Key Laboratory of Quality Research in Chinese Medicine, Institute of Chinese Medical Sciences, University of Macau, Macao, People's

Republic of China

${ }^{2}$ Institute of Traditional Chinese Medicine \& Natural Products, and Guangdong Provincial Engineering Research Center for Modernization of TCM, College of Pharmacy, Jinan University, Guangzhou 510632, People's Republic of China
}

$[2,3]$. Natural products offer more drug-like features to molecules from combinatorial chemistry in terms of functional groups, chirality, and structural complexity $[4$, 5].

The amounts of active ingredients in natural medicines are always fairly low. The lab-intensive and time-consuming extraction and isolation process has been the bottle neck of the application of natural products in drug development. There is an urgent need to develop effective and selective methods for the extraction and isolation of bioactive natural products. This review intends to provide a comprehensive view of a variety of methods used in the extraction and isolation of natural products.

\section{Extraction}

Extraction is the first step to separate the desired natural products from the raw materials. Extraction methods include solvent extraction, distillation method, pressing and sublimation according to the extraction principle. Solvent extraction is the most widely used method. The extraction of natural products progresses through the following stages: (1) the solvent penetrates into the solid matrix; (2) the solute dissolves in the solvents; (3) the solute is diffused out of the solid matrix; (4) the extracted solutes are collected. Any factor enhancing the diffusivity and solubility in the above steps will facilitate the extraction. The properties of the extraction solvent, the particle size of the raw materials, the solvent-to-solid ration, the 
extraction temperature and the extraction duration will affect the extraction efficiency [6-10].

The selection of the solvent is crucial for solvent extraction. Selectivity, solubility, cost and safety should be considered in selection of solvents. Based on the law of similarity and intermiscibility (like dissolves like), solvents with a polarity value near to the polarity of the solute are likely to perform better and vice versa. Alcohols $(\mathrm{EtOH}$ and $\mathrm{MeOH})$ are universal solvents in solvent extraction for phytochemical investigation.

Generally, the finer the particle size is, the better result the extraction achieves. The extraction efficiency will be enhanced by the small particle size due to the enhanced penetration of solvents and diffusion of solutes. Too fine particle size, however, will cost the excessive absorption of solute in solid and difficulty in subsequent filtration.

High temperatures increase the solubility and diffusion. Temperatures that too high, however, may cause solvents to be lost, leading to extracts of undesirable impurities and the decomposition of thermolabile components.

The extraction efficiency increases with the increase in extraction duration in a certain time range. Increasing time will not affect the extraction after the equilibrium of the solute is reached inside and outside the solid material.

The greater the solvent-to-solid ratio is, the higher the extraction yield is; however, a solvent-to-solid ratio that is too high will cause excessive extraction solvent and requires a long time for concentration.

The conventional extraction methods, including maceration, percolation and reflux extraction, usually use organic solvents and require a large volume of solvents and long extraction time. Some modern or greener extraction methods such as super critical fluid extraction (SFC), pressurized liquid extraction (PLE) and microwave assisted extraction (MAE), have also been applied in natural products extraction, and they offer some advantages such as lower organic solvent consumption, shorter extraction time and higher selectivity. Some extraction methods, however, such as sublimation, expeller pressing and enfleurage are rarely used in current phytochemical investigation and will not discussed in this review. A brief summary of the various extraction methods used for natural products is shown in Table 1.

\section{Maceration}

This is a very simple extraction method with the disadvantage of long extraction time and low extraction efficiency. It could be used for the extraction of thermolabile components.
Ćujić et al. achieved high yields of total phenols and total anthocyanins from chokeberry fruit at an optimized condition with $50 \%$ ethanol, a solid-solvent ratio of 1:20 and particle size of $0.75 \mathrm{~mm}$, which suggested that maceration was a simple and effective method for the extraction of phenolic compounds from chokeberry fruit [11]. A study on the extraction of catechin (1, Fig. 1) from Arbutus unedo L. fruits using maceration, microwaveassisted and ultrasound extraction techniques showed that microwave-assisted extraction (MAE) was the most effective, but a lower temperature was applied in maceration with nearly identical extraction yields, which can be translated into economic benefits [12]. Jovanović et al. evaluated the extraction efficiency of polyphenols from Serpylli herba using various extraction techniques (maceration, heat assisted extraction and ultrasonic-assisted extraction). Based on the content of total polyphenols, ultrasonic-assisted extraction produced the highest total flavonoids yield and no statistically significant difference were found between maceration and heat assisted extraction [13]. Cajanus cajan leaves are used in Chinese folk medicine for the treatment of hepatitis, chickenpox and diabetes. Flavonoids are the bioactive compounds. Jin et al. compared extraction rates of orientoside (2), luteolin (3), and total flavonoids from C. cajan leaves by microwave-assisted method, reflux extraction, ultrasound-assisted extraction, and maceration extraction. The extraction efficiency of orientoside, luteolin, and total flavonoids was found to be the lowest in the extract from maceration method [14].

\section{Percolation}

Percolation is more efficient than maceration because it is a continuous process in which the saturated solvent is constantly being replaced by fresh solvent.

Zhang et al. compared the percolation and refluxing extraction methods to extract Undaria pinnatifida. They found that the contents of the major component, fucoxanthin (4, Fig. 2), from the percolation extraction method was higher than that from the refluxing method while there was no significant difference in extract yield between the two methods [15]. Goupi patch is a compound Chinese medicine preparation consisting of 29 Chinese medicines. Fu et al. used the whole alkaloids content determined by acid-base titration as the index and optimized the ethanol percolation method as soaking the medicine with $55 \%$ alcohol for $24 \mathrm{~h}$ and then percolating with 12 times the amount of 55\% alcohol [16]. When using the extracting rate of sinomenine (5) and 
Table 1 A brief summary of various extraction methods for natural products

\begin{tabular}{|c|c|c|c|c|c|c|}
\hline Method & Solvent & Temperature & Pressure & Time & $\begin{array}{l}\text { Volume of organic } \\
\text { solvent consumed }\end{array}$ & $\begin{array}{l}\text { Polarity of natural } \\
\text { products extracted }\end{array}$ \\
\hline Maceration & $\begin{array}{l}\text { Water, aqueous } \\
\text { and non-aqueous } \\
\text { solvents }\end{array}$ & Room temperature & Atmospheric & Long & Large & $\begin{array}{l}\text { Dependent on extract- } \\
\text { ing solvent }\end{array}$ \\
\hline Percolation & $\begin{array}{l}\text { Water, aqueous } \\
\text { and non-aqueous } \\
\text { solvents }\end{array}$ & $\begin{array}{l}\text { Room temperature, } \\
\text { occasionally under } \\
\text { heat }\end{array}$ & Atmospheric & Long & Large & $\begin{array}{l}\text { Dependent on extract- } \\
\text { ing solvent }\end{array}$ \\
\hline Decoction & Water & Under heat & Atmospheric & Moderate & None & Polar compounds \\
\hline Reflux extraction & $\begin{array}{l}\text { Aqueous and non- } \\
\text { aqueous solvents }\end{array}$ & Under heat & Atmospheric & Moderate & Moderate & $\begin{array}{l}\text { Dependent on extract- } \\
\text { ing solvent }\end{array}$ \\
\hline Soxhlet extraction & Organic solvents & Under heat & Atmospheric & Long & Moderate & $\begin{array}{l}\text { Dependent on extract- } \\
\text { ing solvent }\end{array}$ \\
\hline $\begin{array}{l}\text { Pressurized liquid } \\
\text { extraction }\end{array}$ & $\begin{array}{l}\text { Water, aqueous } \\
\text { and non-aqueous } \\
\text { solvents }\end{array}$ & Under heat & High & Short & Small & $\begin{array}{l}\text { Dependent on extract- } \\
\text { ing solvent }\end{array}$ \\
\hline $\begin{array}{l}\text { Supercritical fluid } \\
\text { extraction }\end{array}$ & $\begin{array}{l}\text { Supercritical fluid } \\
\left.\text { (usually } \mathrm{S}-\mathrm{CO}_{2}\right) \text {, } \\
\text { sometimes with } \\
\text { modifier }\end{array}$ & $\begin{array}{l}\text { Near room tempera- } \\
\text { ture }\end{array}$ & High & Short & None or small & $\begin{array}{l}\text { Nonpolar to moderate } \\
\text { polar compounds }\end{array}$ \\
\hline $\begin{array}{l}\text { Ultrasound assisted } \\
\text { extraction }\end{array}$ & $\begin{array}{l}\text { Water, aqueous } \\
\text { and non-aqueous } \\
\text { solvents }\end{array}$ & $\begin{array}{l}\text { Room temperature, or } \\
\text { under heat }\end{array}$ & Atmospheric & Short & Moderate & $\begin{array}{l}\text { Dependent on extract- } \\
\text { ing solvent }\end{array}$ \\
\hline $\begin{array}{l}\text { Microwave assisted } \\
\text { extraction }\end{array}$ & $\begin{array}{l}\text { Water, aqueous } \\
\text { and non-aqueous } \\
\text { solvents }\end{array}$ & Room temperature & Atmospheric & Short & None or moderate & $\begin{array}{l}\text { Dependent on extract- } \\
\text { ing solvent }\end{array}$ \\
\hline $\begin{array}{l}\text { Pulsed electric field } \\
\text { extraction }\end{array}$ & $\begin{array}{l}\text { Water, aqueous } \\
\text { and non-aqueous } \\
\text { solvents }\end{array}$ & $\begin{array}{l}\text { Room temperature, or } \\
\text { under heat }\end{array}$ & Atmospheric & Short & Moderate & $\begin{array}{l}\text { Dependent on extract- } \\
\text { ing solvent }\end{array}$ \\
\hline $\begin{array}{l}\text { Enzyme assisted } \\
\text { extraction }\end{array}$ & $\begin{array}{l}\text { Water, aqueous } \\
\text { and non-aqueous } \\
\text { solvents }\end{array}$ & $\begin{array}{l}\text { Room temperature, or } \\
\text { heated after enzyme } \\
\text { treatment }\end{array}$ & Atmospheric & Moderate & Moderate & $\begin{array}{l}\text { Dependent on extract- } \\
\text { ing solvent }\end{array}$ \\
\hline $\begin{array}{l}\text { Hydro distillation and } \\
\text { steam distillation }\end{array}$ & Water & Under heat & Atmospheric & Long & None & $\begin{array}{l}\text { Essential oil (usually } \\
\text { non-polar) }\end{array}$ \\
\hline
\end{tabular}<smiles>Oc1cc(O)c2c(c1)O[C@H](c1ccc(O)c(O)c1)[C@H](O)C2</smiles>

1 (+)-catechin<smiles>O=c1cc(-c2ccc(O)cc2)oc2c(C3OCCC(O)C(O)C3O)c(O)cc(O)c12</smiles>

2 orientoside<smiles>O=c1cc(-c2ccc(O)c(O)c2)oc2cc(O)cc(O)c12</smiles>

3 luteolin

Fig. 1 Structures of compounds $\mathbf{1}-\mathbf{3}$

ephedrine hydrochloride (6) as the index, Gao developed another optimized percolation method: soaking the medicine with $70 \%$ ethanol for $24 \mathrm{~h}$ and then percolating with 20 times the amount of $70 \%$ ethanol. The transfer rates of sinomenine and ephedrine hydrochloride were 78.23 and $76.92 \%$, respectively [17].

\section{Decoction}

The extract from decoction contains a large amount of water-soluble impurities. Decoction cannot be used for the extraction of thermolabile or volatile components.

The ginsenosides $(7-31)$ in ginseng encounter hydrolysis, dehydration, decarboxylation and addition reactions 
<smiles>CC(=O)O[C@@H]1C[C@](C)(O)C(=C=C/C(C)=C/C=C/C(C)=C/C=C/C=C(C)/C=C/C=C(\C)C(=O)C[C@]2(C)[C@@H](C)CC(C)CC2(C)C)[C@](C)(O)C1</smiles>

4 fucoxanthin<smiles>COC1=C[C@H]2N(C)[C@H]3C[C@]2(CC1=O)c1c3ccc(OC)c1O</smiles><smiles>CN[C@@H](C)[C@H](O)c1ccccc1</smiles>

5 sinomenine

6 ephedrine hydrochloride

Fig. 2 Structures of compounds 4-6

during decocting (Fig. 3) [18]. Zhang et al. investigated the chemical transformation of a famous TCM preparation, Danggui Buxue Tang, an herbal decoction containing Astragali Radix and Angelicae Sinensis Radix. They found that two flavonoid glycosides, calycosin-7-O- $\beta$ D-glucoside (32, Fig. 4) and ononin (33), in Astragali Radix, could be hydrolyzed to form calycosin (34) and formononetin (35), respectively, during decocting. The hydrolysis efficiency was strongly affected by $\mathrm{pH}$, temperature, and the amount of herbs [19]. Two compounds of TCM, Sanhuang Xiexin Tang (SXT) and Fuzi Xiexin Tang (FXT), have been used in China for the treatment of diseases such as diabetes for thousands of years. SXT is composed of Rhei Radix et Rhizoma, Scutellariae Radix and Coptidis Rhizoma while FXT is produced by adding another TCM, Aconiti Lateralis Radix Preparata, in SXT. Zhang et al. applied an UPLC-ESI/MS method to monitor 17 active constituents in SXT and FXT decoctions and macerations. The decoction process might enhance the dissolution of some bioactive compounds compared with the maceration process. The contents of 11 constituents [benzoylaconine (36), benzoylhypaconine (37), benzoylmesaconine (38), berberine (39), coptisine (40), palmatine (41), jatrorrhizine (42), aloe-emodin (43) and emodin (44), baicalin (45), wogonoside (46)] in decoctions of SXT and FXT were significantly higher than those in macerations of SXT and FXT. The $\beta$-glucuronidase in herbs could catalyze the hydrolysis of the glucuronic acid group from glycosides (baicalin and wogonoside) to transfer into aglycones [baicalein (47) and wogonin (48)]. The high temperature in the decoction process deactivated the activity of the $\beta$-glucuronidase and prevented the transformation of glycosides to their aglycones, which led to the discovery of the higher contents of baicalin and wogonoside in decoctions as well as the higher contents of baicalein and wogonin in macerations. The interaction between chemicals from different herbs was also observed. The diester-diterpenoid alkaloids were not detected in the decoction and maceration of FXT, but diester-diterpenoid alkaloid hypaconitine (49) was found in the decoction of the single herb Aconiti Lateralis Radix Preparata. The constituents of the other three herbs in FXT might promote the transformation from diester-diterpenoid alkaloids in Aconiti Lateralis Radix Preparata to other less toxic monoester-diterpenoid alkaloids, which might explain the mechanism of toxicity reduction and efficacy enhancement of TCM by formulation [20].

\section{Reflux extraction}

Reflux extraction is more efficient than percolation or maceration and requires less extraction time and solvent. It cannot be used for the extraction of thermolabile natural products.

Refluxing with $70 \%$ ethanol provided the highest yield of the natural bio-insecticidal, didehydrostemofoline (50, Fig. 5) (0.515\% w/w of the extract), from Stemona collinsiae root among the extracts prepared by different extraction methods (sonication, reflux, Soxhlet, maceration and percolation) [21]. Zhang compared the extraction efficiency of active ingredients (baicalin (45, Fig. 4) and puerarin (51) from a TCM compound composing seven herbs with two different methods, decoction and 

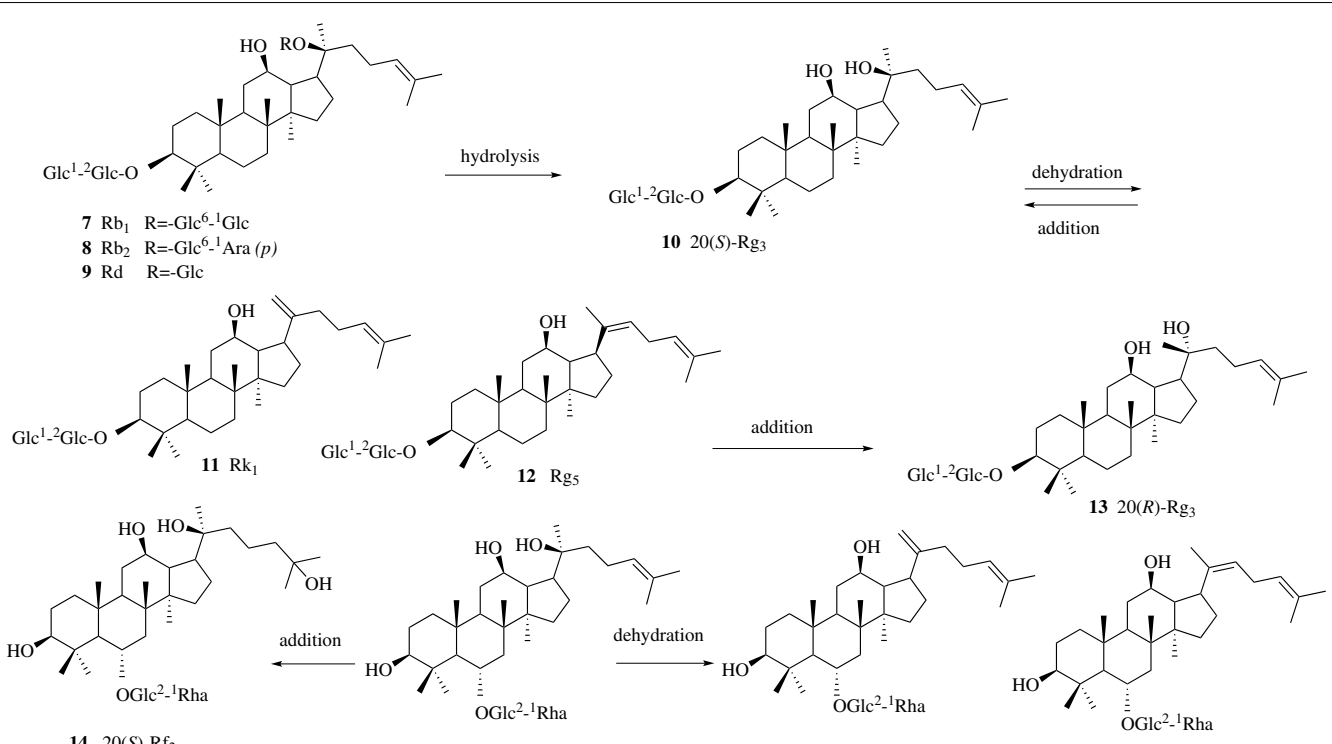

$1420(S)-\mathrm{Rf}_{2}$

$1520(S)-\operatorname{Rg}_{2}$

$16 \operatorname{Rg}_{6}$

$17 \quad \mathrm{~F}_{4}$

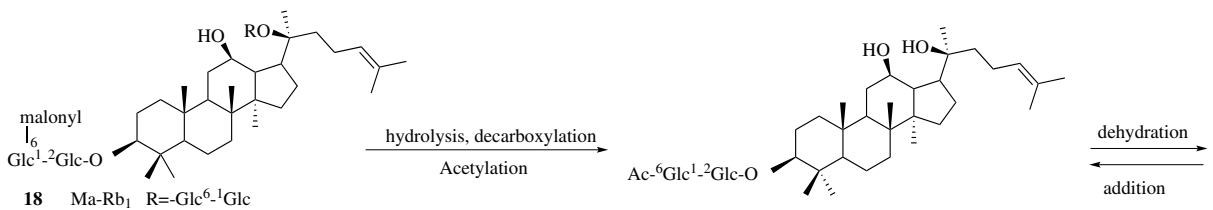

$18 \quad \mathrm{Ma}-\mathrm{Rb}_{1} \quad \mathrm{R}=-\mathrm{Glc}^{6}{ }_{-1}{ }^{\mathrm{Glc}}$

$19 \quad \mathrm{Ma}-\mathrm{Rb}_{2} \quad \mathrm{R}=-\mathrm{Glc}^{6}-{ }^{-1} \mathrm{Ara}(p)$

$20 \begin{array}{lll}\text { Ma-Rc } & \mathrm{R}=-\mathrm{Glc}^{6}-{ }^{1} \mathrm{Ara}(f)\end{array}$

21 Ma-Rd $\mathrm{R}=-$ Glc

$22 \mathrm{Ma}^{-\mathrm{Rb}_{3}} \mathrm{R}=-\mathrm{Glc}^{6}-{ }^{1} \mathrm{xyl}$
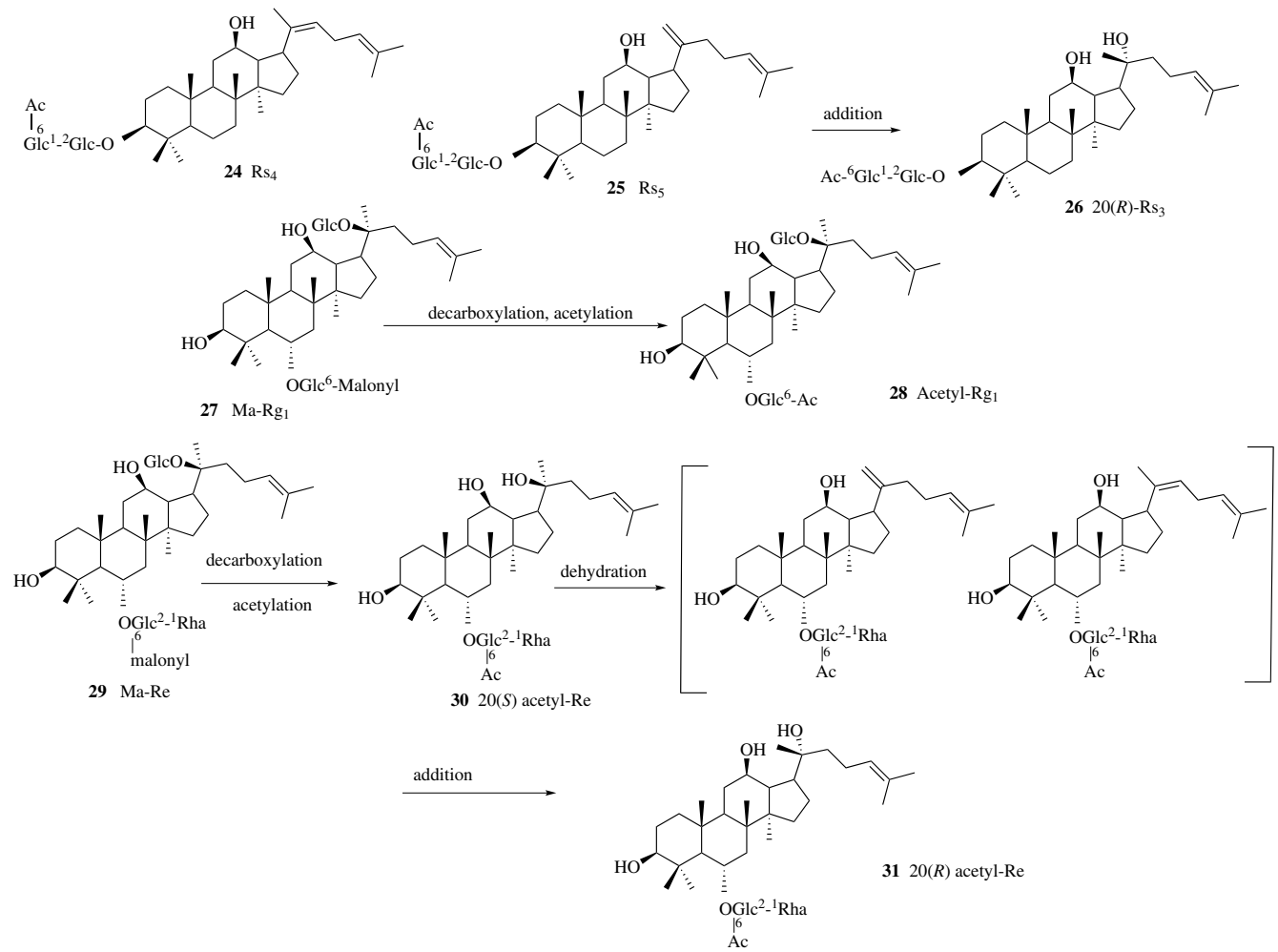

Fig. 3 Possible mechanisms of the chemical conversion of ginsenosides (7-31) in decoction 
<smiles></smiles>

32 calycosin-7- $O-\beta$-D-glucoside $\quad \mathrm{R}=\mathrm{OH}$ 33 ononin<smiles>[R]c1cc(-c2coc3cc(O)ccc3c2=O)ccc1OC</smiles>

34 calycosin $\quad \mathrm{R}=\mathrm{OH}$ 35 formononetin $\mathrm{R}=\mathrm{H}$

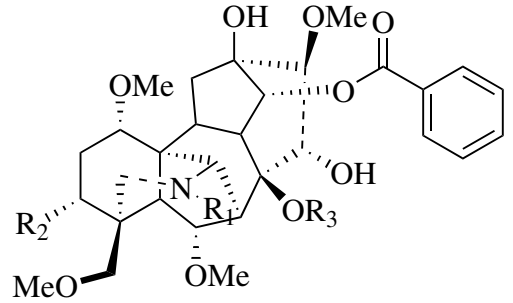

36 benzoylaconine 37 benzoylhypaconine 38 benzoylmesaconine 49 hypaconitine

$\mathrm{R}_{1}=\mathrm{C}_{2} \mathrm{H}_{5} \quad \mathrm{R}_{2}=\mathrm{OH} \quad \mathrm{R} 3=\mathrm{H}$

$\mathrm{R}_{1}=\mathrm{CH}_{3} \quad \mathrm{R}_{2}=\mathrm{H} \quad \mathrm{R} 3=\mathrm{H}$

$\mathrm{R}_{1}=\mathrm{CH}_{3} \quad \mathrm{R}_{2}=\mathrm{OH} \quad \mathrm{R} 3=\mathrm{H}$

$\mathrm{R}_{1}=\mathrm{CH}_{3} \quad \mathrm{R}_{2}=\mathrm{H} \quad \mathrm{R} 3=\mathrm{COCH}_{3}$<smiles>[R4]Oc1ccc2cc3[n+](cc2c1O[R16])CCc1cc([R20])c([R20])cc1-3</smiles>

$\begin{array}{llll}\mathrm{R}_{1} & \mathrm{R}_{2} & \mathrm{R}_{3} & \mathrm{R}_{4}\end{array}$

39 berberine

40 coptisine

41 palmatine

42 jatrorrhizine

78 columbamine

79 groenlandicine

$\mathrm{CH}_{2}$

$\mathrm{CH}_{2}$

$\mathrm{CH}_{3} \mathrm{CH}_{3} \mathrm{CH}_{3} \mathrm{CH}_{3}$

$\begin{array}{lllll}\mathrm{H} & \mathrm{CH}_{3} & \mathrm{CH}_{3} & \mathrm{CH}_{3}\end{array}$

$\begin{array}{llll}\mathrm{CH}_{3} & \mathrm{H} & \mathrm{CH}_{3} & \mathrm{CH}_{3}\end{array}$

$\begin{array}{llll}\mathrm{H} & \mathrm{CH}_{3} & \mathrm{CH}_{2}\end{array}$<smiles>[R20]c1c([R])c(O)c2c(=O)cc(-c3ccccc3)oc2c1[R]</smiles>

45 baicalin $\quad \mathrm{R}_{1}=\mathrm{OH} \quad \mathrm{R}_{2}=$ GluA $\mathrm{R}_{3}=\mathrm{H}$

46 wogonoside $\mathrm{R}_{1}=\mathrm{H} \quad \mathrm{R}_{2}=$ GluA $\mathrm{R}_{3}=\mathrm{OCH}_{3}$

47 baicalein $\quad \mathrm{R}_{1}=\mathrm{OH} \quad \mathrm{R}_{2}=\mathrm{H} \quad \mathrm{R}_{3}=\mathrm{H}$

48 wogonin $\quad \mathrm{R}_{1}=\mathrm{H} \quad \mathrm{R}_{2}=\mathrm{H} \quad \mathrm{R}_{3}=\mathrm{OCH}_{3}$

Fig. 4 Structures of compounds $\mathbf{3 2 - 4 8}$ and $\mathbf{7 8 - 7 9}$

reflux. The reflux method was found to be better than the decoction method and the highest yields of baicalin and puerarin were obtained from the reflux method with $60 \%$ ethanol as the extraction solvent [22].

\section{Soxhlet extraction}

The Soxhlet extraction method integrates the advantages of the reflux extraction and percolation, which utilizes the principle of reflux and siphoning to continuously extract the herb with fresh solvent. The Soxhlet extraction is an automatic continuous extraction method with high extraction efficiency that requires less time and solvent consumption than maceration or percolation. The high temperature and long extraction time in the Soxhlet extraction will increase the possibilities of thermal degradation.

Wei et al. obtained ursolic acid (52, Fig. 6) from the TCM Cynomorium (Cynomorii Herba) with a yield of $38.21 \mathrm{mg} / \mathrm{g}$ by Soxhlet extraction [23]. The degradation of catechins in tea was also observed in Soxhlet extraction due to the high extraction temperature applied. The concentrations of both total polyphenols and total alkaloids from the Soxhlet extraction method at $70{ }^{\circ} \mathrm{C}$ decreased compared to those from the maceration method applied under $40^{\circ} \mathrm{C}[24,27]$. 


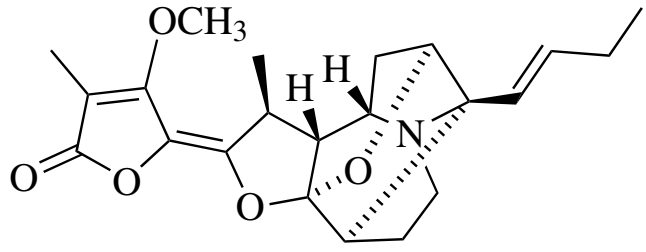

50 didehydrostemofoline

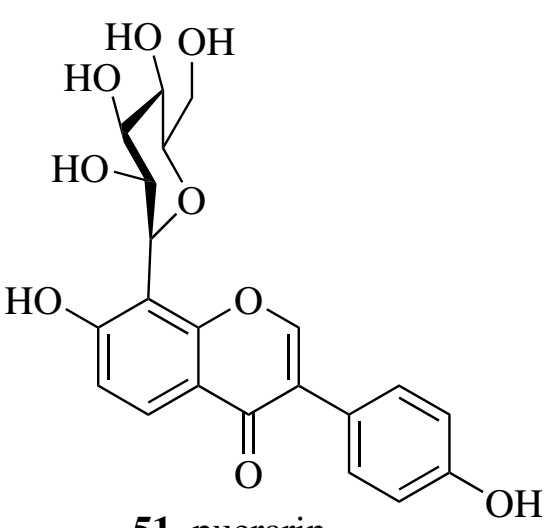

51 puerarin

Fig. 5 Structures of compounds $\mathbf{5 0 - 5 1}$

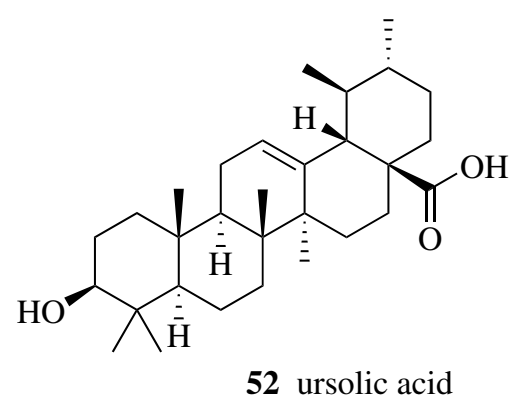

Fig. 6 Structure of compounds $\mathbf{5 2}$

\section{Pressurized liquid extraction (PLE)}

Pressurized liquid extraction (PLE) has also been described as accelerated solvent extraction, enhanced solvent extraction, pressurized fluid extraction, accelerated fluid extraction, and high pressure solvent extraction by different research groups. PLE applies high pressure in extraction. High pressure keeps solvents in a liquid state above their boiling point resulting in a high solubility and high diffusion rate of lipid solutes in the solvent, and a high penetration of the solvent in the matrix. PLE dramatically decreased the consumption of extraction time and solvent and had better repeatability compared to other methods.

Pressurized liquid extraction has been successfully applied by the researchers at the University of Macau and other institutes in extracting many types of natural products including saponins, flavonoids and essential oil from TCM [8, 25-27]. Some researchers believed PLE could not be used to extract thermolabile compounds due to the high extraction temperature, while others believed it could be used for the extraction of thermolabile compounds because of the shorter extraction time used in
PLE. Maillard reactions occurred when PLE was used at $200{ }^{\circ} \mathrm{C}$ to extract antioxidants from grape pomace [28]. Anthocyanins are thermolabile. Gizir et al. successfully applied PLE to obtain an anthocyanin-rich extract from black carrots because the degradation rate of anthocyanins is time-dependent, and the high-temperature-shortduration PLE extraction conditions could overcome the disadvantage of high temperature employed in the extraction [29].

\section{Supercritical fluid extraction (SFE)}

Supercritical fluid extraction (SFE) uses supercritical fluid (SF) as the extraction solvent. SF has similar solubility to liquid and similar diffusivity to gas, and can dissolve a wide variety of natural products. Their solvating properties dramatically changed near their critical points due to small pressure and temperature changes. Supercritical carbon dioxide $\left(\mathrm{S}-\mathrm{CO}_{2}\right)$ was widely used in SFE because of its attractive merits such as low critical temperature $\left(31{ }^{\circ} \mathrm{C}\right)$, selectivity, inertness, low cost, non-toxicity, and capability to extract thermally labile compounds. The low polarity of S- $-\mathrm{CO}_{2}$ makes it ideal for the extraction of non-polar natural products such as lipid and volatile oil. A modifier may be added to $\mathrm{S}-\mathrm{CO}_{2}$ to enhance its solvating properties significantly.

Conde-Hernández extracted the essential oil of rosemary (Rosmarinus officinalis) by S- $\mathrm{CO}_{2}$ extraction, hydro distillation and steam distillation. He found that both yields of essential oil and antioxidant activity of SFC extract were higher than those from other two methods [30]. S- $\mathrm{CO}_{2}$ modified with $2 \%$ ethanol at 300 bar and $40{ }^{\circ} \mathrm{C}$ gave higher extracting selectivity of vinblastine (53, Fig. 7) (an antineoplastic drug) from Catharanthus roseus, which is $92 \%$ more efficient for vinblastine extraction compared to traditional extraction methods [31]. 


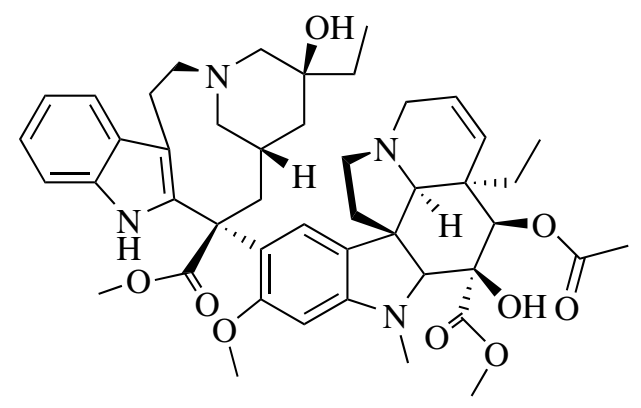

53 vinblastine

Fig. 7 Structure of compounds $\mathbf{5 3}$

\section{Ultrasound assisted extraction (UAE)}

Ultrasonic-assisted extraction (UAE), also called ultrasonic extraction or sonication, uses ultrasonic wave energy in the extraction. Ultrasound in the solvent producing cavitation accelerates the dissolution and diffusion of the solute as well as the heat transfer, which improves the extraction efficiency. The other advantage of UAE includes low solvent and energy consumption, and the reduction of extraction temperature and time. $\mathrm{UAE}$ is applicable for the extraction of thermolabile and unstable compounds. UAE is commonly employed in the extraction of many types of natural products $[32,33]$.
Jovanović et al. achieved a higher yield of polyphenols from Thymus serpyllum L. by UAE at an optimized condition (50\% ethanol as solvent; 1:30 solid-to-solventratio; $0.3 \mathrm{~mm}$ particle size and $15 \mathrm{~min}$ time) than maceration and heat-assisted extraction methods [13]. Wu et al. found that there was no statistically significant difference for extracting ginsenosides, including ginsenosides Rg1 (54, Fig. 8) and Rb1 (7, Fig. 3), chikusetsusaponins V (55), IV (56) and IVa (57), and pseudoginsenoside RT1 (58), from the TCM Panacis Japonici Rhizoma between UAE and reflux using $70 \%$ aqueous methanol to extract for $30 \mathrm{~min}$ [34]. Guo et al. found both the reflux method and UAE had the advantages of time-saving, convenient operation and high extract yield and that UAE is relatively better than reflux methods for TCM Dichroae Radix using the extract yield and content of febrifugine (59) as the indexes [35].

\section{Microwave assisted extraction (MAE)}

Microwaves generate heat by interacting with polar compounds such as water and some organic components in the plant matrix following the ionic conduction and dipole rotation mechanisms. The transfers of heat and mass are in the same direction in MAE, which generates a synergistic effect to accelerate extraction and improve extraction yield. The application of MAE provides many advantages, such as increasing the extract yield,

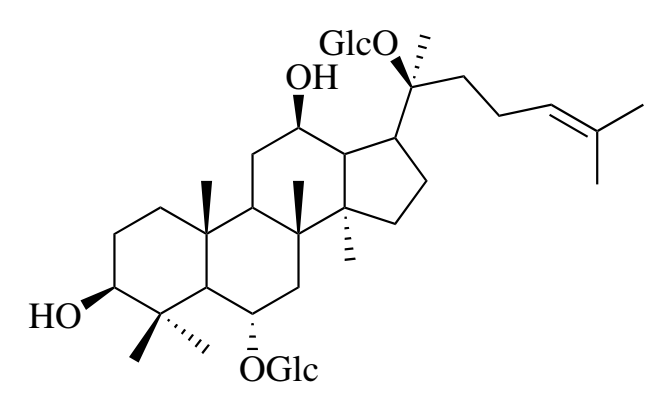

54 ginsenoside $\operatorname{Rg} 1$<smiles>O=C(C[C@@H]1NCCC[C@H]1O)Cn1cnc2ccccc2c1=O</smiles><smiles>[R20][C@H]1CC[C@@]2(C)[C@@H](CC[C@H]3[C@H]2CC=C2[C@@H]4CC(C)(C)CC[C@]4(C(=O)OC)CC[C@@]23C)C1(C)C</smiles>

55 chikusetsusaponin V R=-GluA ${ }^{2}{ }^{1}$ Glc

56 chikusetsusaponin IV $\mathrm{R}=-\mathrm{GluA}{ }^{4}-{ }^{1}$ Ara

57 chikusetsusaponin IVa $\mathrm{R}=-\mathrm{GluA}$

58 pseudoginsenoside RT1 R=-GluA ${ }^{2}{ }^{1} \mathrm{Xyl}$

59 febrifugine

Fig. 8 Structures of compounds 54-59 
decreasing the thermal degradation and selective heating of vegetal material. MAE is also regraded as a green technology because it reduces the usage of organic solvent. There are two types of MAE methods: solvent-free extraction (usually for volatile compounds) and solvent extraction (usually for non-volatile compounds) [36, 37].

Chen optimized the conditions for MAE to extract resveratrol (60, Fig. 9) from the TCM Polygoni Cuspidati Rhizoma et Radix (the rhizome and radix of Polygonum cuspidatum) by orthogonal experiment. An extraction yield of $1.76 \%$ of resveratrol was obtained from the optimized conditions as follows: extraction time $7 \mathrm{~min}, 80 \%$ ethanol, ratio of liquid to solid 25:1 (ml:g), microwave power $1.5 \mathrm{kw}$ [38]. Benmoussa et al. employed the enhanced solvent-free MAE method for the extraction of essential oils from Foeniculum vulgare Mill. seeds at atmospheric pressure without any addition of solvent or water. The yield and aromatic profile in the enhanced solvent-free MAE extract was similar to those extracted by hydro distillation and cost only one-sixth of the time of hydro distillation [39]. Xiong et al. developed an MAE to extract five main bioactive alkaloids, liensinine (61), neferine (62), isoliensinine (63), dauricine (64), and nuciferin (65), from the TCM Nelumbinis Plumula (lotus plumule, the green embryo of Nelumbo nucifera seeds) using univariate approach experiments and central composite design. The MAE conditions was optimized as follows: $65 \%$ methanol as the extraction solvent, microwave power of $200 \mathrm{~W}$ and extraction time of $260 \mathrm{~s}$ [40, 44].

\section{Pulsed electric field (PEF) extraction}

Pulsed electric field extraction significantly increases the extraction yield and decreased the extraction time because it can increase mass transfer during extraction by destroying membrane structures. The effectiveness of PEF treatment depends on several parameters including<smiles>Oc1ccc(/C=C/c2cc(O)cc(O)c2)cc1</smiles>

60 E-resveratrol<smiles>[R1]Oc1ccc(C[C@H]2c3cc(Oc4cc(C[C@@H]5c6cc(O[R20])c(OC)cc6CCN5C)ccc4O)c(OC)cc3CCN2C)cc1</smiles><smiles>COc1cc2c(cc1OC)[C@@H](Cc1ccc(Oc3cc(C[C@@H]4c5cc(OC)c(OC)cc5CCN4C)ccc3O)cc1)N(C)CC2</smiles>

64 dauricine<smiles>COc1cc2c3c(c1OC)-c1ccccc1C[C@H]3N(C)CC2</smiles>
61 liensinine
$\mathrm{R}_{1}=\mathrm{H}$
$\mathrm{R}_{2}=\mathrm{CH}_{3}$
62 neferine
$\mathrm{R}_{1}=\mathrm{CH}_{3} \quad \mathrm{R}_{2}=\mathrm{CH}_{3}$
63 isoliensinine
$\mathrm{R}_{1}=\mathrm{CH}_{3} \quad \mathrm{R}_{2}=\mathrm{H}$

Fig. 9 Structures of compounds 60-65 
field strength, specific energy input, pulse number and treatment temperature. PEF extraction is a non-thermal method and minimizes the degradation of the thermolabile compounds.

Hou et al. obtained the highest yield of the ginsenosides $(12.69 \mathrm{mg} / \mathrm{g})$ by PEF using the conditions of $20 \mathrm{kV} /$ $\mathrm{cm}$ electric field intensity, $6000 \mathrm{~Hz}$ frequency, $70 \%$ ethanol-water solution, and $150 \mathrm{l} / \mathrm{h}$ velocity. The yield of the ginsenosides of the PEF extraction method is higher than those of MAE, heat reflux extraction, UAE and PLE. The entire PEF extraction process took less than $1 \mathrm{~s}$ and much less than the other tested methods [41]. In a study of antioxidants extracted from Norway spruce bark, Bouras found that much higher phenolic content (eight times) and antioxidant activity (30 times) were achieved after the PEF treatment compared to untreated samples [42].

\section{Enzyme assisted extraction (EAE)}

The structure of the cell membrane and cell wall, micelles formed by macromolecules such polysaccharides and protein, and the coagulation and denaturation of proteins at high temperatures during extraction are the main barriers to the extraction of natural products. The extraction efficiency will be enhanced by EAE due to the hydrolytic action of the enzymes on the components of the cell wall and membrane and the macromolecules inside the cell which facilitate the release of the natural product. Cellulose, $\alpha$-amylase and pectinase are generally employed in EAE.

Polysaccharide is one of the bioactive ingredients in the TCM Astragali Radix. Chen et al. studied the EAE of polysaccharide from the radix of Astragalus membranaceus using various enzymes and found that glucose oxidase offered better performance in extracting polysaccharide than the other seven enzymes tested (amyloglucosidase, hemicellulase, bacterial amylase, fungal amylase, pectinase, cellulose and vinozyme). The polysaccharide yield under the optimized EAE condition using glucose oxidase increased more than $250 \%$ compared with that from non-enzyme treated method [43]. The extraction yield of chlorogenic acid (66, Fig. 10) from Eucommia ulmoides leaves was greatly improved when using cellulase and ionic liquids [44]. Strati el al. found that carotenoid and lycopene (67) extraction yields from tomato waste were increased by the use of pectinase and cellulase enzymes. Compared to the non-enzyme treated solvent extraction method, sixfold and tenfold higher yields of the two target compounds were obtained in samples treated with cellulase and pectinase, respectively [45].

\section{Hydro distillation and steam distillation}

Hydro distillation (HD) and steam distillation (SD) are commonly used methods for the extraction of volatile oil. Some natural compounds encounter decomposition in HD and SD.

The chemical composition and antibacterial activity of the primary essential oil and secondary essential oil from Mentha citrata were significantly affected by distillation methods. Both primary essential oil and secondary essential oil yields by HD were higher than those by SD $[46,50]$. Yahya and Yunus found that the extraction time did affect the quality of the essential patchouli oil extracted. When the extraction time increased, the contents of some components decreased or increased [47].

\section{Separation methods}

The components in the extract from above methods are complex and contain a variety of natural products that require further separation and purification to obtain the active fraction or pure natural products. The separation<smiles>O=C(/C=C/c1ccc(O)c(O)c1)O[C@H]1C[C@](O)(C(=O)O)C[C@H](O)[C@H]1O</smiles>

66 chlorogenic acid

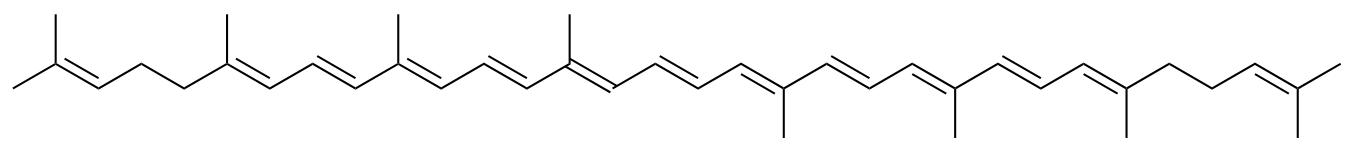

67 lycopene

Fig. 10 Structures of compounds $\mathbf{6 6 - 6 7}$ 
depends on the physical or chemical difference of the individual natural product. Chromatography, especially column chromatography, is the main method used to obtain pure natural products from a complex mixture.

\section{Separation based on adsorption properties}

Adsorption column chromatography is widely used for the separation of natural products, especially in the initial separation stage, due to its simplicity, high capacity and low cost of adsorbents such as silica gel and macroporous resins. The separation is based on the differences between the adsorption affinities of the natural products for the surface of the adsorbents. The selection of adsorbents (stationary phase) as well as the mobile phase is crucial to achieve good separation of natural products, maximize the recovery of target compounds and avoid the irreversible adsorption of target compounds onto the adsorbents.

Silica gel is the most widely used adsorbent in phytochemical investigation. It was estimated that nearly $90 \%$ of phytochemical separation (preparative scale) was based on silica gel. Silica gel is a polar absorbent with silanol groups. Molecules are retained by the silica gel through hydrogen bonds and dipole-dipole interactions. Thus, polar natural products are retained longer in silica gel columns than nonpolar ones. Sometimes, certain polar natural products might undergo irreversible chemisorption. The deactivation of silica gel by adding water before use or using a water-containing mobile phase will weaken the adsorption. Severe tailing may occur when separating alkaloids on silica gel, and the addition of a small amount of ammonia or organic amines such as triethylamine may reduce the tailing. Twelve alkaloids belonging to the methyl chanofruticosinate group including six new alkaloids, prunifolines A-F (68-73, Fig. 11), were obtained from the leaf of Kopsia arborea by initial silica gel column chromatography using gradient $\mathrm{MeOH}-\mathrm{CHCl}_{3}$ as the mobile phase followed by centrifugal TLC using ammonia saturated $\mathrm{Et}_{2} \mathrm{O}$-hexane or EtOAc/hexane systems as the eluent [48].

Alumina (aluminum oxide) is a strong polar adsorbent used in the separation of natural products especially in the separation of alkaloids. The strong positive field of $\mathrm{Al}^{3+}$ and the basic sites in alumina affecting easily polarized compounds lead to the adsorption on alumina that is different from that on silica gel. The application of alumina in the separation of natural products has decreased significantly in recent years because it can catalyze dehydration, decomposition or isomerization during separation. Zhang and Su reported a chromatographic protocol using basic alumina to separate taxol (74, Fig. 11) from the extract of Taxus cuspidate callus cultures and found the recovery of taxol was more than $160 \%$. They found that the increase of taxol came from the isomerization of 7-epi-taxol (75) catalyzed by alumina. It was also found that a small amount of taxol could be decomposed to baccatin III (76) and 10-deacetylbaccatin III (77) in the alumina column [49]. Further investigation into the separation of taxol on acidic, neutral and basic alumina indicated that the Lewis souci and the basic activity cores on the surface of alumina induced the isomerization of 7-epi-taxol to taxol [50].

The structures of polyamides used in chromatography contain both acryl and amide groups. Hydrophobic and/ or hydrogen bond interaction will occur in polyamide column chromatography depending on the composition of the mobile phase. When polar solvents such as aqueous solvents are used as the mobile phase, the polyamides act as the non-polar stationary phase and the chromatography behavior is similar to reversed-phase chromatography. In the contrast, the polyamides act as the polar stationary phase and the chromatography behavior is similar to normal phase chromatography. Polyamide column chromatography is a conventional tool for the separation of natural polyphenols including anthraquinones, phenolic acids and flavonoids, whose mechanisms are ascribed to hydrogen bond formation between polyamide absorbents, mobile phase and target compounds. Gao et al. studied the chromatography behavior of polyphenols including phenolic acids and flavonoids on polyamide column. It was found that the polyamide functioned as a hydrogen bond acceptor, and the numbers of phenolic hydroxyls and their positions in the molecule affected the strength of adsorption [51]. In addition to polyphenols, the separation of other types of natural products by polyamide column chromatography were also reported. The total saponins of Kuqingcha can be enriched by polyamide column chromatography, which significantly reduced the systolic pressure of SHR rat [52]. Using a mixture of dichloromethane and methanol in a gradient as the eluent, the seven major isoquinoline alkaloids in Coptidis Rhizoma including berberine (39), coptisine (40), palmatine (41), jatrorrhizine (42), columbamine (78), groenlandicine (79) (Fig. 4), and magnoflorine (80, Fig. 11) were separated in one-step polyamide column chromatography [53].

Adsorptive macroporous resins are polymer adsorbents with macroporous structures but without ion exchange groups that can selectively adsorb almost any type of natural products. They have been widely used either as a standalone system, or as part of a pretreatment process for removing impurities or enriching target compounds due to their advantages, which include high adsorptive capacity, relatively low cost, easy regeneration and easy scale-up. The adsorptive mechanisms of adsorptive macroporous resins include electrostatic forces, 


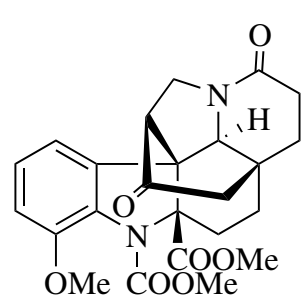

68 prunifoline $\mathrm{A}$

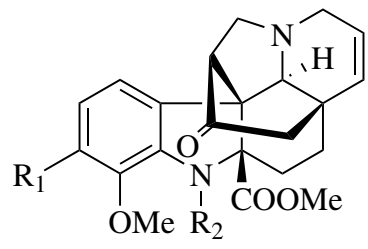

69 prunifoline $\mathrm{B} \mathrm{R}_{1}=\mathrm{OMe}, \mathrm{R}_{2}=\mathrm{COOMe}$

70 prunifoline $C \mathrm{R}_{1}=\mathrm{H}, \quad \mathrm{R}_{2}=\mathrm{H}$

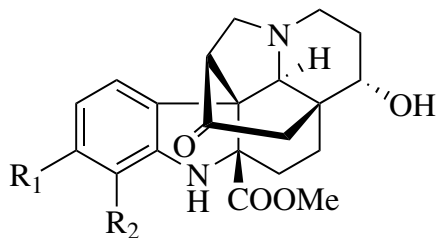

71 prunifoline $\mathrm{D} \quad \mathrm{R}_{1}=\mathrm{H}, \quad \mathrm{R}_{2}=\mathrm{H}$

72 prunifoline $\mathrm{E} \mathrm{R}_{1} \mathrm{R}_{2}=\mathrm{OCH}_{2} \mathrm{O}$

73 prunifoline $\mathrm{F} \quad \mathrm{R}_{1}=\mathrm{H}, \quad \mathrm{R}_{2}=\mathrm{OMe}$<smiles>O=CCC(NC(=O)c1ccccc1)c1ccccc1</smiles>

$\mathrm{HO}$

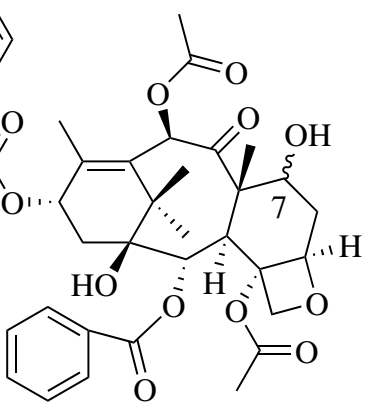

74 taxol $7 S$

75 7-epi-taxol $7 R$<smiles>COc1cc2c(c(O)c1O)-c1c(ccc(OC)c1O)CC2</smiles>

80 magnoflorine

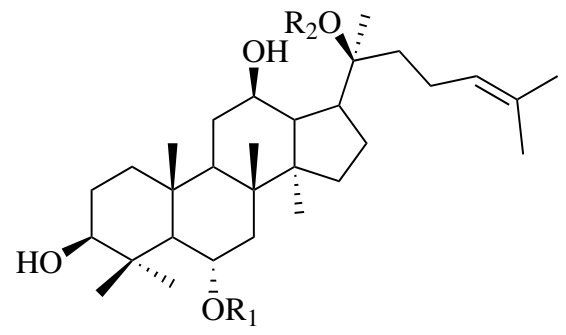

81 PTS $\mathrm{R}_{1}, \mathrm{R}_{2}=\mathrm{H}$ or glycosyl

87 notoginsenoside R1 $\mathrm{R}_{1}=\mathrm{Glc}^{2}{ }^{1} \mathrm{Xyl} \quad \mathrm{R}_{2}=\mathrm{Glc}$ 88 ginsenoside $\mathrm{Re} \quad \mathrm{R}_{1}=\mathrm{Glc}^{2}-{ }^{1} \mathrm{Rha} \mathrm{R}_{2}=\mathrm{Glc}$

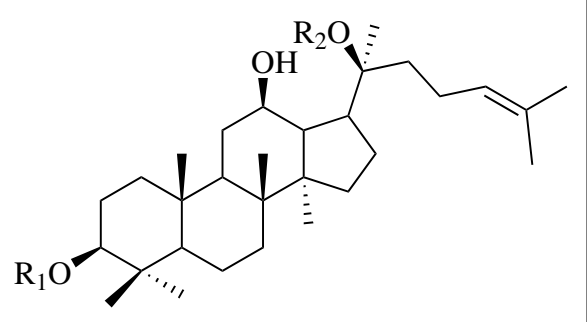

82 PDS $\mathrm{R}_{1}, \mathrm{R}_{2}=\mathrm{H}$ or glycosyl

76 baccatin III $\quad \mathrm{R}=\mathrm{CH}_{3} \mathrm{CO}$

77 10-deacetylbaccatin III $\mathrm{R}=\mathrm{H}$<smiles>C=C(C)CCC(CC1(CC=C(C)C)C(=O)C2C(CCC)CC(=O)OC2C(O)=C2C(=O)[C@H](C)[C@@H](C)OC21)C(=C)C</smiles>

83 brasiliensic acid<smiles>C=C(C)C(CC=C(C)C)CC1(CC=C(C)C)C(=O)C(C(CCC)CC(=O)O)C2OC(C)[C@@H](C)C(=O)C2=C1O</smiles>

84 isobrasiliensic acid<smiles>[R]C(C)C[C@@]12C(=C)C(=O)[C@](CC=C(C)C)(C(=O)C(C(=O)c3ccc(O)c(O)c3)=C1O)C2(C)CC(C)C</smiles>

85 xanthochymol $\mathrm{R}=$ 86 guttiferone $E R=$

Fig. 11 Structures of compounds $\mathbf{6 8 - 8 8}$ 
hydrogen bonding, complex formation and size-sieving actions between the resins and the natural products in solution. Surface area, pore diameter and polarity are the key factors affecting the capacity of the resins [54]. $20(S)$-protopanaxatriol saponins (PTS) (81) and 20(S)protopanaxadiol saponins (PDS) (82, Fig. 11) are known as two major bioactive components in the root of Panax notoginseng. PTS and PDS were successfully separated with 30 and $80 \%(\mathrm{v} / \mathrm{v})$ aqueous ethanol solutions from the D101 macroporous resin column, respectively. The chromatography behaviors of PDS and PTS were close to reversed-phase chromatography when comparing the chromatographic profiles of macroporous resin column chromatography to the HPLC chromatogram on a Zorbax SB- $\mathrm{C}_{18}$ column [55]. Recently, Meng et al. obtained the total saponins of Panacis Japonici Rhizoma (PJRS) using D101 macroporous resin. The contents of the four major saponins, chikusetsusaponins V (55), IV (56) and IVa (57), and pseudoginsenoside RT1 (58) (Fig. 8), in the obtained PJRS was more than 73\%. The PJRS served as the standard reference for quality control of Panacis Japonici Rhizoma [56]. Some researchers assumed that the principal adsorptive mechanism between macroporous resins and polyphenols was associated with the hydrogen bonding formation between the oxygen atom of the ether bond of the resin and the hydrogen atom of phenolic hydroxyl group of the phenol. The hydrogen bonding interaction force was significantly affected by the $\mathrm{pH}$ value of the solution $[57,58]$.

Silver nitrate is another useful solid support in the separation of natural products. Those natural products containing the $\pi$ electrons reversibly interact with silver ions to form polar complexes. The greater the number of double bonds or aromaticity of the natural product, the stronger the complexation forms. Silver nitrate is typically impregnated on silica gel (SNIS) or alumina for separation. Several research groups reported the separation of fatty acids on SNIS [59-61]. Wang et al. reported the isolation of zingiberene from ginger oleoresin by SNIS column chromatography [62]. A pair of isomers, brasiliensic acid (83, Fig. 11) and isobrasiliensic acid (84), were separated from Calophyllum brasiliense by Lemos et al. on an SNIS column [63, 69]. Some research groups also applied silver nitrate in the two-phase system in high-speed counter-current chromatography (HSCCC) to improve the separation. Xanthochymol (85) and guttiferone $E(\mathbf{8 6})$ are a pair of $\pi$ bond benzophenone isomers from Garcinia xanthochymus by $\mathrm{AgNO}_{3}-\mathrm{HSCCC}$. The elution order of the $\pi$ bond isomers in this $\mathrm{AgNO}_{3}-\mathrm{HSCCC}$ separation is internal $\pi$ bond (earlier) $<$ terminal, which is identical to that observed from SNIS column chromatography [64].

\section{Separation based on partition coefficient}

Partition chromatography (PC) follows the liquid-liquid extraction principle based on the relative solubility in two different immiscible liquids. In the early stage, one liquid phase was coated to a solid matrix (silica gel, carbon, cellulose, etc.) as the stationary phase and another liquid phase was employed as the mobile phase. The disadvantage of an easily removed stationary phase and unrepeatable results has led to this kind of PC being rarely used today. The bonded-phase, in which the liquid stationary phase is chemically bound to the inert support, which is used as the stationary phase overcomes those drawbacks. Commercially available alkyl such as C8 and C18, aryl, cyano and amino substituted silanes are often used as bonded phases, which are widely used to separate a variety of natural products, especially in the final purification step.

Three PTS (notoginsenoside R1 (87) (Fig. 11), ginsenosides $\operatorname{Rg} 1$ (55) (Fig. 8) and $\operatorname{Re}(\mathbf{8 8})$ (Fig. 11)) and two PDS [ginsenosides Rb1 (7) and Rd (9)] (Fig. 3) were well separated in a $\mathrm{C} 18$ column using the $\mathrm{EtOH}-\mathrm{H}_{2} \mathrm{O}$ system as the mobile phase [65]. A novel polyacrylamide-based silica stationary phase was synthesized by Cai et al. and was successfully applied in the separation of galactooligosaccharides and saponins of Paris polyphylla with EtOH$\mathrm{H}_{2} \mathrm{O}$ as the mobile phase [66].

Counter-current chromatography (CCC) is kind of PC that holds the liquid stationary phase by gravity or centrifugal force. CCC has rarely been used in early stages due to its poor stationary retention, long separation time and labor intensive process. CCC was significantly improved in the 1980s, however, when modern CCC, including HSCCC and centrifugal partition chromatography (CPC), were developed. The hydrodynamic CCC systems such as HSCCC have a planetary rotation movement around two rotating axes with no rotating seals, which offers a low pressure drop process. Hydrostatic CCC, e.g., centrifugal partition chromatography, uses only one rotating axis and has a series of interconnecting chambers to trap the stationary phase which offers a higher retention of the stationary phase and a higher system pressure than that of HSCCC. The high system pressure in CPC prevents the improvement of the resolution by increasing the length of the column. High performance CCC (HPCCC) represents a new generation of hydrodynamic CCC and works in the same way as HSCCC, but with a much higher g-level. The HPCCC instruments generate more than $240 \mathrm{~g}$, while early HSCCC equipment gave g-levels of less than $80 \mathrm{~g}$. HPCCC shortens the separation time to less than an hour compared to several hours in previous HSCCC and can achieve at least ten times the throughput of an HSCCC instrument [67]. Compared to the conventional 
column separation method using a solid stationary phase, both hydrostatic and hydrodynamic CCC systems offer some advantages including the elimination of irreversible adsorption and peak tailing, high loading capacity, high sample recovery, minimal risk of sample denaturation and low solvent consumption. The limitation of CCC is that it only separates the compounds in a relatively narrow polarity window. Over the past 20 years, HSCCC, HPCCC and CPC attracted great attention in separation science and have been widely used in the separation of natural products. Tang et al. developed an HSCCC method using a two-phase solvent system comprising ethyl acetate- $n$-butanol-ethanol-water $(4: 2: 1.5: 8.5, \mathrm{v} / \mathrm{v} /$ v/v) to separate six flavone $C$-glycosides (89-94, Fig. 12), including two novel compounds from Lophatherum gracile [68]. HSCCC, HPCCC and CPC have also been successfully applied in the separation of volatile oil, which is difficult to separate via conventional column chromatography. Six volatile compounds (curdione (95), curcumol (96), germacrone (97), curzerene (98), 1,8-cineole (99) and $\beta$-elemene (100)) were isolated by CPC from the essential oil of Curcuma wenyujin using a nonaqueous two-phase solvent system consisting of petroleum etheracetonitrile-acetone $(4: 3: 1 \mathrm{v} / \mathrm{v} / \mathrm{v})$ [69]. Four major sesquiterpenoids (ar-turmerone (101), $\alpha$-turmerone (102), $\beta$-turmerone (103), and $E$-atlantone (104)) with similar structures were separated from the essential oil of Curcuma longa in a single HSCCC run using a two-phase solvent system composed of $n$-heptane-ethyl acetateacetonitrile-water $(9.5 / 0.5 / 9 / 1, \mathrm{v} / \mathrm{v})$ and each compound achieved over $98 \%$ purity [70]. Linalool (105), terpinen4-ol (106), $\alpha$-terpineol (107), $p$-anisaldehyde (108), anethole (109) and foeniculin (110) were successfully isolated from the essential oil of Pimpinella anisum by HPCCC using a stepwise gradient elution [71]. Li et al. developed a CPC method for the separation of patchouli alcohol (111) with a nonaqueous ether-acetonitrile $(1: 1, \mathrm{v} / \mathrm{v})$ solvent system. More than $2 \mathrm{~g}$ of patchouli alcohol with over 98\% purity were isolated from $12.5 \mathrm{~g}$ of essential oil over a $240 \mathrm{ml}$ column [72]. The large volume (several liters) column has been adopted in commercial hydrostatic CCC and hydrodynamic CCC equipment for pilot/industrial scale separation. Few reports could be obtained due to commercial confidentiality. It is difficult to judge whether hydrostatic or hydrodynamic CCC is better for industrial applications. Users might select different types of CCC instrument for different purposes. When the stationary phase is poorly retained in hydrodynamic CCC due to high viscosity and small density differences between the mobile and stationary phases, the hydrostatic CCC is more practical than hydrodynamic CCC because the retention of the stationary phase of hydrostatic CCC is less sensitive to the physical properties of liquid systems and will have a higher retention of the stationary phase. When the stationary phase is well retained in hydrodynamic CCC, higher separation efficiency will be obtained from hydrodynamic CCC than from hydrostatic CCC with the same liquid system and similar column volumes because hydrostatic CCC has relatively low partition efficiency due to a limited degree of mixing, and the hydrodynamic system provides efficient mixing to yield a high partition efficiency.

\section{Separation based on the molecular size}

The separation of natural products by membrane filtration (MF) or gel filtration chromatography (GFC) is based on their molecular sizes.

\section{Membrane filtration (MF)}

In MF, the semipermeable membrane allows smaller molecules to pass through and retains the larger molecules. MF of natural products could be characterized as microfiltration, ultrafiltration, and nanofiltration based on the pore size of the membrane applied.

Membrane filtration has been a powerful tool for the concentration, clarification and removal of impurities in the lab, as well as in the food and pharmaceutical industries. The contents of total phenols (338\%), chlorogenic acid (66) (Fig. 10) (483\%), theobromine (112, Fig. 13) (323\%), caffeine (113) (251\%), condensed tannins (278\%) and saponins $(211 \%)$ in the aqueous extract of Ilex paraguariensis were significantly increased by nanofiltration [73, 80]. Coupling membrane filtration is applied when a single membrane filtration step is not satisfactory. A sequence of microfiltration, ultrafiltration and nanofiltration was applied in the isolation of bioactive components from olive leaf extract. Microfiltration followed by ultrafiltration removed the impurities larger than $5 \mathrm{kDa}$. Nanofiltration recovered the antioxidative and antibacterial polyphenols and flavonoids, and the content of the major component, oleuropein (114), in the nanofiltration retentate was concentrated approximately ten times [74].

\section{Gel filtration chromatography (GFC)}

Gel filtration chromatography is also known as gel permeation chromatography or size exclusion chromatography. The small molecules have a longer retention time in GFC than large molecules.

Sephadex is formed by cross-linking dextran, and the G-types of Sephadex were used for the separation of hydrophilic compounds such as peptides [75], oligosaccharides and polysaccharides [76].

Sephadex LH20, a hydroxypropylated derivative of Sephadex G25, has both hydrophobic and hydrophilic natures. An adsorption mechanism was also involved in separation using Sephadex LH-20. Sephadex LH-20 can 
<smiles>[R]O[C@]1([R])C2=CC([R])=C1C(O)=C1C(=O)C=C(c3ccc(O)c([R9])c3)C=C1O2</smiles><smiles>O=c1cc(-c2ccc(O)c(O)c2)oc2cc(OC3OC(O)C(O)COC3C(O)CO)c(CO)c(O)c12</smiles>

93 luteolin 6- $C$ - $\alpha$-L-arabinopyranosyl-7- $O-\beta$-D-glucopyranoside<smiles>C/C=C\CC(=O)C(CC(=O)C(C)C)C(C)C</smiles><smiles>C=C1C[C@]2(O)O[C@]3(C[C@@H]1C(C)C)C(C)CCC23</smiles>

96 curcumol<smiles>C=CC1(C)CCC(C(=C)C)CC1C(=C)C</smiles>

$100 \beta$-elemene<smiles>C=CC(C)(O)CCCC(C)C</smiles><smiles>CC(C)=CC(=O)CC(C)c1ccc(C)cc1</smiles>

101 ar-turmerone<smiles>CC1=CCC(O)(C(C)C)CC1</smiles>

105 linalool<smiles>CC(C)=CCC1=C(C)CC(C)=CCC1=O</smiles>

97 germacrone<smiles>C=C1C=CC(C(C)CC(=O)C=C(C)C)CC1</smiles>

$102 \alpha$-turmerone<smiles>CC1=CCC(C(C)(C)O)CC1</smiles>

$107 \alpha$-terpineol<smiles>O=c1cc(-c2ccc(O)c(O)c2)oc2c(C3OCCC(O)C(O)CC3O)c(O)cc(O)c12</smiles>

94 orientin<smiles>C=C[C@]1(C)Cc2occ(C)c2C[C@H]1C(=C)C</smiles>

98 curzerene<smiles>CC(C)=CC(=O)CC(C)C1C=CC(C)=CC1</smiles>

$103 \beta$-turmerone<smiles>COc1ccc(C=O)cc1</smiles>

$108 p$-anisaldehyde<smiles>CC1(C)CCCC1(C)C</smiles>

99 1,8-cineole<smiles>CC(C)=CC(=O)C=C(C)C1CC=C(C)CC1</smiles>

$104 \beta$-atlantone<smiles>C/C=C/c1ccc(OC)cc1</smiles>

109 anethole<smiles>C/C=C/c1ccc(OCC=C(C)C)cc1</smiles>

110 foeniculin

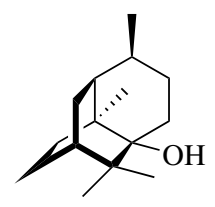

111 patchouli alcohol

Fig. 12 Structures of compounds $\mathbf{8 9 - 1 1 1}$ 


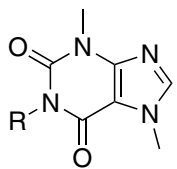

112 theobromine $\mathrm{R}=\mathrm{H}$ 113 caffeine $\mathrm{R}=\mathrm{CH}_{3}$

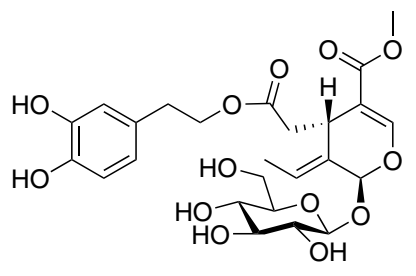

114 oleuropein
Fig. 13 Structures of compounds 112-114

be used for the separation of a wide variety of natural products in either an aqueous or non-aqueous solvent system. The feruloylated arabinoxylan oligosaccharides of perennial cereal grain intermediate wheat were well separated by Sephadex LH-20 using 100\% water as the mobile phase [77]. Three new pyrimidine diterpenes, axistatins 1-3 (115-117, Fig. 14) along with three known formamides (118-120) were isolated from the anti-cancer active $\mathrm{CH}_{2} \mathrm{Cl}_{2}$ fraction of Agelas axifera over Sephadex LH-20 columns with a series of solvent systems $\left[\mathrm{CH}_{3} \mathrm{OH}\right.$, $\mathrm{CH}_{3} \mathrm{OH}-\mathrm{CH}_{2} \mathrm{Cl}_{2}$ (3:2), hexane- $\mathrm{CH}_{3} \mathrm{OH}$-2-propanol (8:1:1), hexane-toluene- $\mathrm{CH}_{2} \mathrm{Cl}_{2}-\mathrm{EtOH}$ (17:1:1:1) and exane-EtOAc- $\mathrm{CH}_{3} \mathrm{OH}$ (4:5:1)], followed by purification using Prep-HPLC $[78,85,87]$.

Polyacrylamide (bio-gel P) [79] and cross-linked agarose [80] were also used in the separation of natural products.

\section{Separation based on ionic strength}

Ion-exchange chromatography (IEC) separates molecules based on the differences in their net surface charge. Some natural products, such as alkaloids and organic acids possessing a functional group capable of ionization, might be separated by IEC. The charged molecules could be caught and released by ion-exchange resin by changing the ionic strength of the mobile phase (e.g., changing $\mathrm{pH}$ or salt concentration). Cation ion-exchange resins were used for the separation of alkaloids, while the anion ion-exchange resins were used for the separation of natural organic acids and phenols.

The positively charged anthocyanins were separated from the neutral polyphenolic compounds in the XAD-7 treated Actinidia melanandra fruit (kiwifruit) extract using Dowex 50WX8 cation ion-exchange resin [81]. Feng and Zhao used semi-preparative chromatography to separate (-)epigallocatechin-gallate [121, Fig. 15)] and (-)epicatechin-gallate (122) in tea crude extract with polysaccharide-based weakly acidic gel CM-Sephadex C-25 [82]. A new alkaloid, fumonisin $B_{6}$ (123), along with a known alkaloid, fumonisin $\mathrm{B}_{2}(\mathbf{1 2 4})$, was isolated by IEC over Strata X-C mixed-mode RP-cation-exchange resin followed by reverse-phase chromatography from the fungus Aspergillus niger NRRL 326 cultures extract [83].<smiles>CNc1ncnc(N)c1N(C=O)C/C=C(\C)CC[C@@H]1[C@@H]2CCC=C(C)[C@@]2(C)CC[C@H]1C</smiles>

115 axistatin 1<smiles>CNc1ncnc(N)c1N(C=O)C/C=C(\C)CC[C@H]1[C@H](C)CC[C@]2(C)C(C)=CCC[C@H]12</smiles>

116 axistatin 2<smiles>[R]Nc1ncnc(NC)c1N(C=O)C/C=C(\C)CC/C=C(/C)CC[C@]1(C)C(C)=CCC[C@H]1C</smiles>

117 axistatin 3 118 ageline $\mathrm{A}$

$\mathrm{R}=\mathrm{CH}\left(\mathrm{CH}_{3}\right)_{2}$<smiles>CNc1ncnc(N)c1N(C=O)C/C=C(\C)CC[C@H]1[C@H](C)CC[C@]2(C)C(COC(=O)c3ccc[nH]3)=CCC[C@H]12</smiles>

119 ageline $B$<smiles>CC1=CCC[C@H](C)[C@@]1(C)CC/C(C)=C/CC/C(C)=C/C[n+]1cn(C)c2ncnc(N)c21</smiles>

120 agelasine $F$

Fig. 14 Structures of compounds 115-120 


\section{Other modern separation techniques} Molecular distillation (MD)

Molecular distillation separates the molecular by distillation under vacuum at a temperature far below its boiling point. It is a suitable distillation method for separating thermosensitive and high-molecular-weight compounds. Borgarello et al. obtained a thymol (125, Fig. 16) enrichment fraction from oregano essential oil by molecular distillation modeled by artificial neural networks. The obtained fraction had antioxidant properties and could stabilize the sunflower oil [84]. Three kinds of phthalates were effectively removed from sweet orange oil by molecular distillation under the optimal conditions (evaporation temperature of $50{ }^{\circ} \mathrm{C}$, evaporator pressure of $5 \mathrm{kPa}$ and a feed flow rate of $0.75 \mathrm{ml} / \mathrm{min}$ ) [85].

\section{Preparative gas chromatography (Prep-GC)}

Gas chromatography (GC) with high separation efficiency and fast separation and analysis makes it potentially the ideal preparative method for the separation of volatile compounds. The injection port, column, split device and trap device of GC equipment must be modified for preparative separation due to a lack of commercial Prep-GC [86].

Five volatile compounds, namely, curzerene (98) (6.6 mg), $\beta$-elemene (100, Fig. 12) (5.1 mg), curzerenone (126) (41.6 mg), curcumenol (127) (46.2 mg), and curcumenone (128) (21.2 mg) (Fig. 17), were separated from the methanol extract of Curcuma Rhizome by Prep-GC over a stainless steel column packed with $10 \%$ OV-101 ( $3 \mathrm{~m} \times 6 \mathrm{~mm}$, i.d.) after 83 single injections $(20 \mu \mathrm{l})$ [87]. Prep-GC was also applied for the separation of natural isomers. A total of $178 \mathrm{mg}$ of cis-asarone (129) and $82 \mathrm{mg}$ of trans-asarone (130) were obtained from the essential oil of Acorus tatarinowii after 90 single injections $(5 \mu \mathrm{l})$ on the same column as above [88]. Prep-GC has become an important separation method for natural volatile compounds; however, a heavier sample load and the largediameter preparative column employed decreased the efficiency [89]. Meanwhile, the disadvantages of PrepGC, including the lack of commercial Prep-GC equipment, consumption of a large volume of carrier gas, the decomposition of thermolabile compounds under high operation temperature, the difficulties of fraction collection, and low production, still restrict the usage of Prep-GC.

\section{Supercritical fluid chromatography (SFC)}

SFC uses supercritical fluid as the mobile phase. SFC integrates the advantages of both GC and liquid chromatography (LC) as the supercritical fluids possess properties of high dissolving capability, high diffusivity and low viscosity, which allows rapid and efficient separation. Thus, SFC can use a longer column and smaller particles of the stationary phase than HPLC, which provides greater numbers of theoretical plates and better separation. SFC can be used for the separation of non-volatile or thermally labile compounds to which GC is not

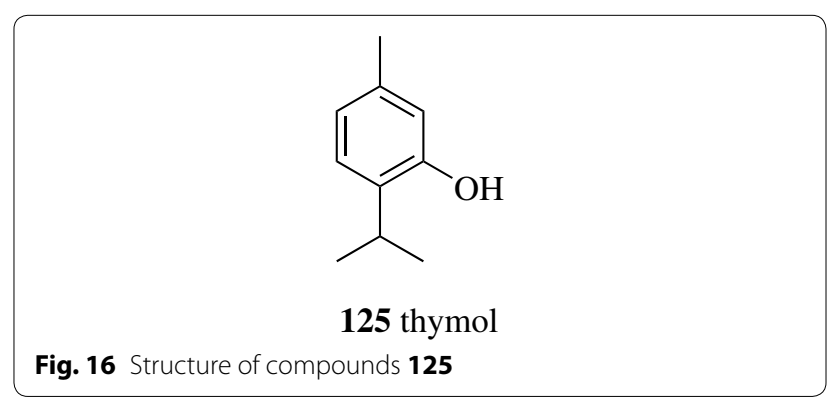<smiles>[R]c1cc([C@H]2Oc3cc(O)cc(O)c3C[C@H]2OC(=O)c2cc(O)c(O)c(O)c2)cc(O)c1O</smiles>

Fig. 15 Structures of compounds 121-124 


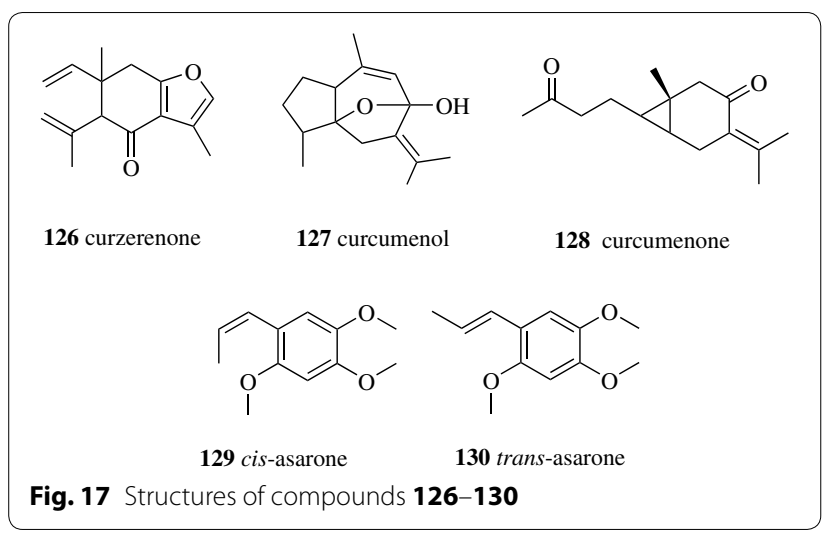

applicable. SFC systems are compatible with a wide range of different detectors including those used in LC and GC systems. The polarity of the widely used mobile phase, $\mathrm{S}-\mathrm{CO}_{2}$, in SFC is close to the polarity of hexane, with the result that SFC was used for the separation of non-polar natural products such as fatty acids, terpenes and essential oils for many years. Eluent modifiers such methanol and acetonitrile enhance the elution strength, which is increasing the interest in separating polar natural products by SFC [90-92].

Zhao et al. successfully separated three pairs of $25 R / S$ diastereomeric spirostanol saponins (131-136, Fig. 18) from the TCM Trigonellae Semen (the seed of Trigonella foenum-graecum) on two CHIRALPAK IC columns coupled in tandem [93]. Yang et al. applied SFC for the preparative separation of two pairs of 7-epimeric spiro oxindole alkaloids (137-140) from stems with hooks of Uncaria macrophylla (a herbal source for TCM Uncariae Ramulus Cum Uncis) on a Viridis Prep Silica 2-EP OBD column using acetonitrile containing $0.2 \%$ DEA modified $\mathrm{S}-\mathrm{CO}_{2}$. The non-aqueous mobile phase used in SFC prevented the tautomerization of the separated spiro oxindole alkaloids [94]. SFC is also applied in the separation of natural enantiomers. $(R, S)$-goitrin $(\mathbf{1 4 1 - 1 4 2 )}$ is the active ingredient of TCM Isatidis Radix. The chiral separation of $(R)$ and $(S)$ goitrins was successfully achieved by prep-SFC on a Chiralpak IC column using acetonitrile as the organic modifier [95].

\section{Molecular imprinted technology}

Molecular imprinted technology has been an attractive separation method in the last decade due to its unique features, which include high selectivity, low cost and easy preparation. Many complementary cavities with the memory of size, shape, and functional groups of the template molecules are generated when the template molecules are removed from the molecular imprinted polymer (MIP). Thus, the template molecule and its analogs will have the specific recognition and selective adsorption for the MIP. MIPs have been widely used in the separation of natural products or as solid-phase extraction sorbents for sample preparation of herbal materials to enrich the minor compounds.

$\mathrm{Ji}$ et al. developed multi-template molecularly imprinted polymers using DL-tyrosine and phenylpyruvic acid as the template molecules to separate dencichine (143, Fig. 19) from the water extract of Panax notoginseng. Both dencichine and the template molecule of DL-tyrosine (144) contain an amino $\left(\mathrm{NH}_{2}\right)$ group and a carboxylic acid $(\mathrm{COOH})$ group, and the other template molecule, phenylpyruvic acid (145), has an $\alpha$-keto acid $(\mathrm{COCOOH})$ group that can also be found in the structure of dencichine [96]. Ma et al. developed a preparative separation method to separate solanesol (146) from tobacco leaves by flash chromatography based on MIP. The MIP was prepared with methyl methacrylate as the monomer, solanesol as the template molecule and ethylene glycol dimethacrylate as the crosslinker by a suspension polymerization method. A total of $370.8 \mathrm{mg}$ of solanesol with 98.4\% purity was separated from the extract of tobacco leaves with a yield of $2.5 \%$ of the dry weight of tobacco leaves [97]. You et al. used the thermo-responsive magnetic MIP to separate the three major curcuminoids, curcumin (147), demethoxycurcumin (148), and bisdemethoxycurcumin (149), from the TCM Curcumae Longae Rhizoma (the rhizome of Curcuma longa). The designed thermo-responsive magnetic MIP showed good imprinting factor for curcuminoids in a range between 2.4 and 3.1, thermo-responsiveness [lower critical solution temperature at $\left.33.71{ }^{\circ} \mathrm{C}\right]$ and rapid magnetic separation $(5 \mathrm{~s})$ [98].

\section{Simulated moving bed chromatography}

Simulated moving bed (SMB) chromatography uses multiple columns with stationary phases (bed). The countercurrent movement of the bed is simulated through rotary valves, which periodically switch the inlet (feed and eluent) and outlet (extract and raffinate). The SMB process is a continuous separation method and a powerful tool for the large-scale separation of natural products with the advantage of lower solvent consumption over a shorter period of time.

Two cyclopeptides, cyclolinopeptides $\mathrm{C}$ and $\mathrm{E}$ (150151, Fig. 20), were obtained from flaxseed oil using a three zone SMBC with eight preparative HPLC normal phase spherical silica gel columns and using absolute ethanol as the desorbent [99]. Kang et al. developed a tandem SMB process consisting of two four-zone SMB units in a series with the same adsorbent particle sizes in Ring I and Ring II to separate paclitaxel (taxol, 74) (Fig. 11), 13-dehydroxybaccatin III (152), and 


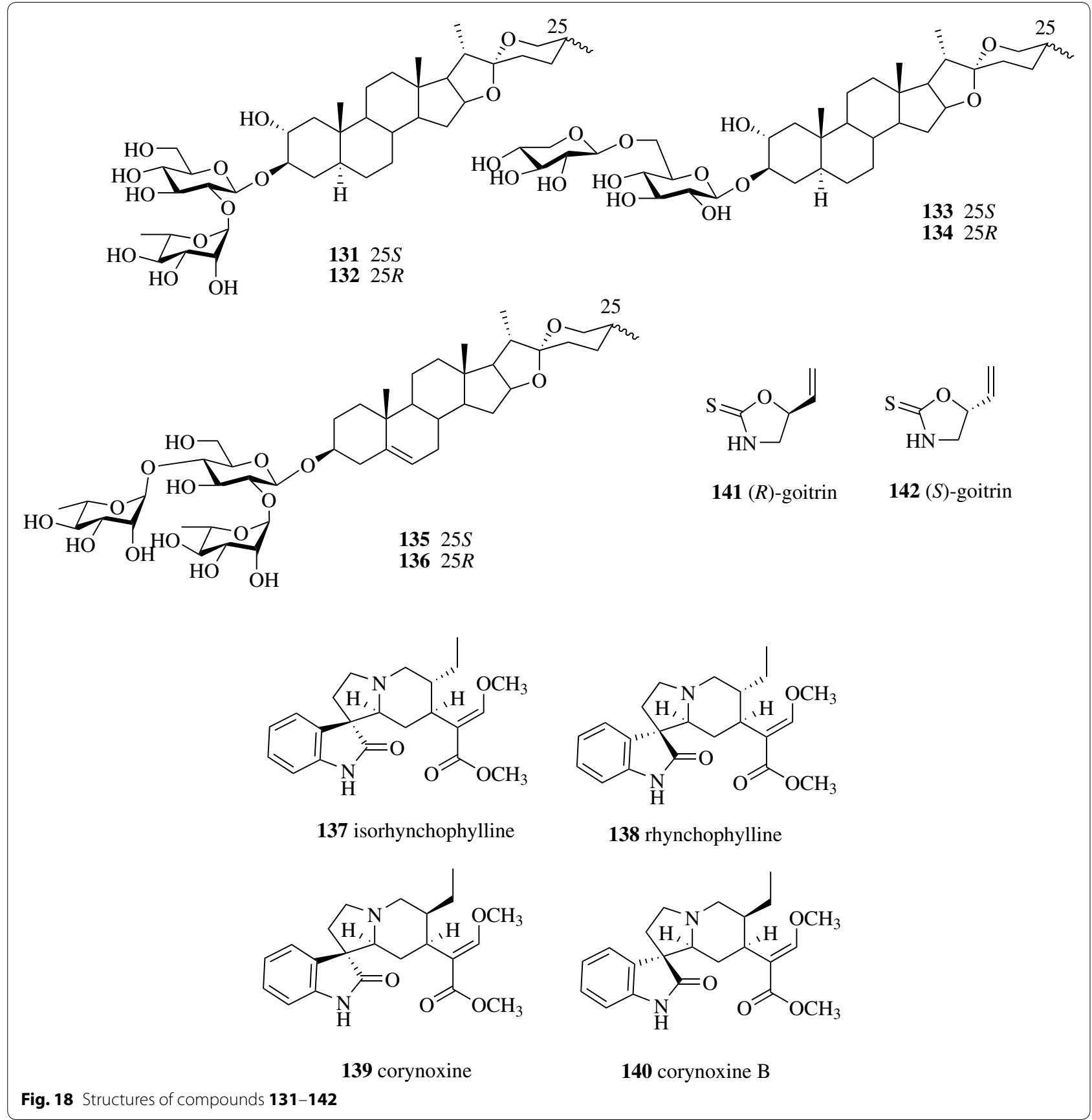

10-deacetylpaclitaxel (153). Paclitaxel was recovered in the first SMB unit while 13-dehydroxybaccatin III and 10-deacetylpaclitaxel were separated in the second SMB unit [100]. Mun enhanced this SMB chromatography method by using different particle sizes adsorbent in Ring I and Ring II [101]. Supercritical fluids can also be used as the desorbent in SMB chromatography. Liang et al. successfully applied supercritical carbon dioxide with ethanol as the desorbent for a three-zone SMB to separate resveratrol (60) (Fig. 9) and emodin (44) (Fig. 4) from a crude extract of the TCM Polygoni Cuspidati Rhizoma et Radix [102].

\section{Multi-dimensional chromatographic separation}

The components in the extract subjected to separation were complex, and generally, no pure compound will be separated in one column chromatography. Multi-dimensional separation based on the solid phase extraction 


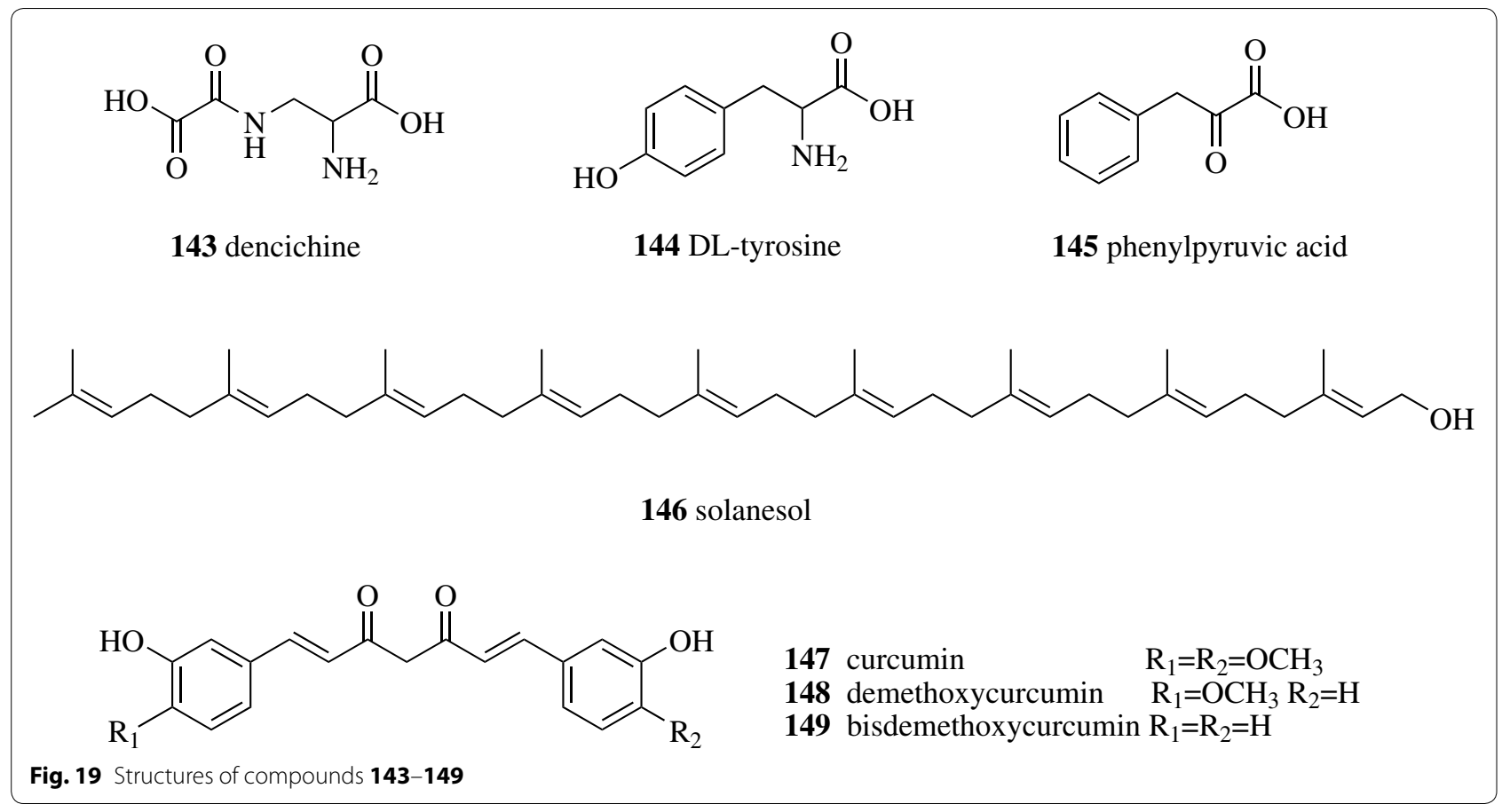

and coupling of multiple columns with different stationary phases greatly improves the separation efficiency. With more commercial multiple dimensional separation equipment entering the market, the separation of natural products is becoming more rapid, efficient and automated.

Usually, the target compound was enriched by first dimensional separation and purified by last dimensional separation. Multi-dimensional separation can be achieved using the same type separation equipment (LC or GC) or different types of equipment (GC and LC). A novel volatile compound, (2E,6E)-2-methyl-6-(4-methylcyclohex-3-enylidene)hept-2-enal (154), was purified by a three-dimensional prep-GC from wampee essential oil [103]. Five antioxidant compounds, including two alkaloids [glusodichotomine AK (155) and glusodichotomine B (156)] and three flavonoids [tricin (157), homoeriodictyol (158) (Fig. 21), and luteolin (3) (Fig. 1)], were separated using a two-dimensional HPLC (RP/HILIC) method from Arenaria kansuensis on a RP-C18HCE and a NP-XAmide preparative columns [104]. Sciarrone et al. exploited the separation of sesquiterpenes in patchouli essential oil by three dimensional Prep-GC. Patchouli alcohol (111, Fig. 12) $(496 \mu \mathrm{g})$ was separated in the first dimension on a poly (5\% diphenyl/95\% dimethylsiloxane) column, and $295 \mu \mathrm{g}$ of $\alpha$-bulnesene (159) was from a second column coated with high molecular weight polyethylene glycol as well as $160 \mu \mathrm{g} \alpha$-guaiene (160) from the third dimension on an ionic-liquid based column (SLB-IL60) [105]. Pantò et al. applied two three-dimensional approaches (GC-GC-GC and LC-GC-GC) to separate the sesquiterpene alcohols $[(Z)-\alpha$-santalol (161), (Z)- $\alpha$-trans bergamotol (162), (Z)- $\beta$-santalol (163), epi-(Z)- $\beta$-santalol (164), $\alpha$-bisabolol (165), (Z)-lanceol (166), and (Z)-nuciferol (167)] from the sandalwood essential oil. They found that the first dimensional separation using $\mathrm{LC}$ reduced the sample complexity and increased the productivity of lowconcentration components [106].

\section{Summary}

Natural products have contributed to drug development over the past few decades and continue to do so. The lab-intensive and time-consuming of extraction and isolation processes, however, have hindered the application of natural products in drug development. As technology continues to develop, more and more new automatic and rapid techniques have been created to extract 


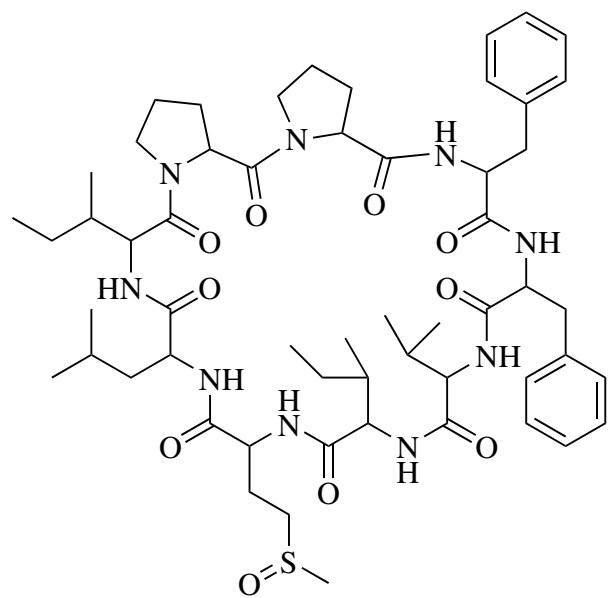

150 cyclolinopeptides C

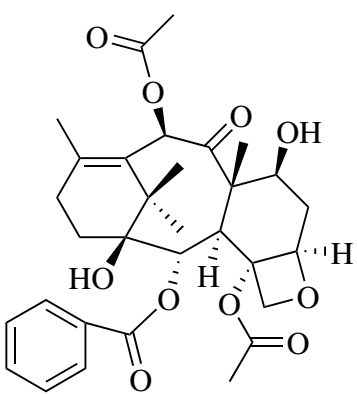

152 13-dehydoxybaccatin III<smiles>CC(C)CC(NC(=O)C(CCS(C)=O)NC(=O)C(CCS(C)=O)NC(=O)C(NC(=O)C(Cc1ccccc1)NC(=O)C1CCCN1C(=O)C(Cc1ccccc1)NC(=O)C(C)C)C(C)C)C(=O)NC(Cc1ccccc1)C(C)C</smiles>

151 cyclolinopeptides E

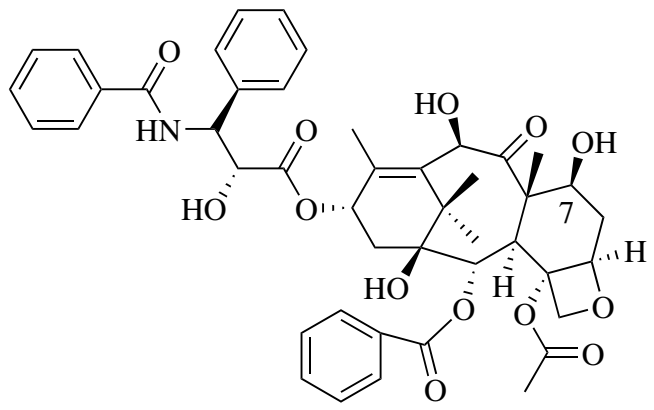

153 10-deacetylpaclitaxel

Fig. 20 Structures of compounds 150-153

and separate natural products, which might reach the requirement of high-throughput screening.

Regarding extraction, reflux extraction is the most commonly employed technique for preparative separation. The modern extraction methods, also regarded as green extraction methods, including UAE, MAE, SFE and PLE, have also been the subject of increased attention in recent years due to their high extraction yields, selectivity, stability of the target extracts and process safety merits. Some of those green methods have become routine sample preparation methods for analytical purposes.

Regarding isolation, the development of novel packing material could enhance the efficiency of isolation, which should be researched further. The hyphenation of chromatographic and spectroscopic or spectrometric techniques with the aim of elucidating structures without the need for isolation, such as LC-NMR and LC-MS, is a useful dereplication tool for searching for novel natural products. Although the isolation of pure natural products from complex mixtures remains challenging and we are far from one-step isolation procedures, the application of more selective methods from extraction to fractionation and purification will speed up the time from collecting biological material to isolating the final purified compound.

In conclusion, there is a clear and increasing interest in the extraction and isolation of natural products and their 
<smiles>CC(C=O)=CCCC(C)=C1CC=C(C)CC1</smiles>

154 (2E,6E)-2-methyl-6-(4methylcyclohex-3-enylidene)hept-2-enal<smiles>[R]c1cc(C2=CC(=O)c3c(O)cc(O)cc3C2)cc(OC)c1O</smiles><smiles>C=C(C)[C@@H]1CCC(C)=C2CC[C@H](C)[C@H]2C1</smiles>

$159 \alpha$-bulnesene<smiles>CC(=CCCC1(C)C2CC=C(C)C1C2)CO</smiles>

$162(Z)-\alpha$-trans bergamotol<smiles>CC(C)=CCC[C@H](C)[C@H]1CC=C(C)CC1</smiles>

$165 \alpha$-bisabolol<smiles>C=C(C)[C@@H]1CC[C@@H](C)C2=C(C1)[C@H](C)CC2</smiles>

$160 \alpha$-guaiene<smiles>C=C1CCCC1CC/C=C(/C)CO</smiles>

163 (Z)- $\beta$-santalol<smiles>C/C(=C/CC[C@@]1(C)C2CC3CC(C)(C2)C31)CO</smiles>

$161(Z)-\alpha$-santalol<smiles>C=C1C2CCC(C2)[C@@]1(C)CC/C=C(/C)CO</smiles>

164 epi-(Z)- $\beta$-santalol

155 glusodichotomine $A K \quad \mathrm{R}_{1}=\mathrm{CH}_{3} \quad \mathrm{R}_{2}=\mathrm{H}$

156 glusodichotomine $B \quad \mathrm{R}_{1}=\mathrm{H} \quad \mathrm{R}_{2}=\mathrm{COOH}$

$\begin{array}{ll}157 \text { tricin } & \mathrm{R}=\mathrm{OCH}_{3} \\ \mathrm{R}=\mathrm{h} & \end{array}$ 
advantageous applications. These specific applications are also conditioning the employed extraction methods and novel stationary phases and mobile phases to be used by these techniques. It is thus expected that these trends will be maintained in the near future as they are mostly motivated by emerging consumer demands and by safety, environmental and regulatory issues.

\begin{abstract}
Abbreviations
CCC: counter-current chromatography; CPC: centrifugal partition chromatography; FXT: Fuzi Xiexin Tang; GC: gas chromatography; GFC: gel filtration chromatography; HD: hydro distillation; HPCCC: high performance countercurrent chromatography; HPLC: high-performance liquid chromatography; HSCCC: high-speed counter-current chromatography; IEC: ion-exchange chromatography; LC: liquid chromatography; MAE: microwave assisted extraction; MD: molecular distillation; MF: membrane filtration; MIP: molecular imprinted polymer; PC: partition chromatography; PDS: 20(S)-protopanaxadiol saponins; PEF: pulsed electric field; PLE: pressurized liquid extraction; PJRS: total saponins of Panacis Japonici Rhizoma; Prep-GC: preparative gas chromatography; PTS: 20(S)-protopanaxatriol saponins; S-CO2: supercritical carbon dioxide; SD: steam distillation; SF: supercritical fluid; SFC: supercritical fluid chromatography; SFE: supercritical fluid extraction; SMB: simulated moving bed; SNIS: impregnated on silica gel; SXT: Sanhuang Xiexin Tang; TCM: traditional Chinese medicine; UAE: ultrasonic-assisted extraction.
\end{abstract}

\section{Authors' contributions}

QWZ designed the study, conducted the literature search, extracted and analyzed data, drafted the manuscript, and is the corresponding author. LGL contributed to the critical revisions of the manuscript. WCY co-designed the study and co-developed the full text of the review, and is the co-corresponding author. All authors read and approved the final manuscript.

\section{Acknowledgements}

Not applicable.

\section{Competing interests}

The authors declare that they have no competing interests.

\section{Availability of data and materials}

All data used in this systematic review are fully available in the public domain.

\section{Consent for publication}

Not applicable.

\section{Ethics approval and consent to participate}

Not applicable.

\section{Funding}

This work was supported by funding from the Macau Science and Technology Development Fund (FDCT/042/2014/A1), Ministry of Science and Technology of China (No. 2013DFM30080), University of Macau (MYRG2014-00162-ICMSQRCM and MYRG2016-00046-ICMS-QRCM).

\section{Publisher's Note}

Springer Nature remains neutral with regard to jurisdictional claims in published maps and institutional affiliations.

Received: 7 January 2018 Accepted: 4 April 2018

Published online: 17 April 2018
References

1. WHO traditional medicine strategy: 2014-2023; 2013. http://www. who.int/medicines/publications/traditional/trm_strategy14_23/en/. Accessed 29 Dec 2017.

2. Newman DJ, Cragg GM. Natural products as sources of new drugs from 1981 to 2014. J Nat Prod. 2016;79(3):629-61.

3. Newman DJ, Cragg GM. Natural products as sources of new drugs over the 30 years from 1981 to 2010. J Nat Prod. 2012;75(3):311-35.

4. Atanasov AG, Waltenberger B, Pferschy-Wenzig EM, Linder T, Wawrosch C, Uhrin P, Temml V, Wang L, Schwaiger S, Heiss EH, et al. Discovery and resupply of pharmacologically active plant-derived natural products: a review. Biotechnol Adv. 2015;33(8):1582-614.

5. Cragg GM, Newman DJ. Natural products: a continuing source of novel drug leads. Biochim Biophys Acta Gen Subj. 2013;1830(6):3670-95.

6. Li P, Xu G, Li SP, Wang YT, Fan TP, Zhao QS, Zhang QW. Optimizing ultra performance liquid chromatographic analysis of 10 diterpenoid compounds in Salvia miltiorrhiza using central composite design. J Agric Food Chem. 2008;56(4):1164-71.

7. Li P, Yin ZQ, Li SL, Huang XJ, Ye WC, Zhang QW. Simultaneous determination of eight flavonoids and pogostone in Pogostemon cablin by high performance liquid chromatography. J Liq Chromatogr Relat Technol. 2014:37(12):1771-84.

8. Yi Y, Zhang QW, Li SL, Wang Y, Ye WC, Zhao J, Wang YT. Simultaneous quantification of major flavonoids in "Bawanghua", the edible flower of Hylocereus undatus using pressurised liquid extraction and high performance liquid chromatography. Food Chem. 2012;135(2):528-33.

9. Zhou YQ, Zhang QW, Li SL, Yin ZQ, Zhang XQ, Ye WC. Quality evaluation of semen oroxyli through simultaneous quantification of 13 components by high performance liquid chromatography. Curr Pharm Anal. 2012;8(2):206-13.

10. Du G, Zhao HY, Song YL, Zhang QW, Wang YT. Rapid simultaneous determination of isoflavones in Radix puerariae using high-performance liquid chromatography-triple quadrupole mass spectrometry with novel shell-type column. J Sep Sci. 2011;34(19):2576-85.

11. Ćujić N, Šavikin K, Janković T, Pljevljakušić D, Zdunić G, Ibrić S. Optimization of polyphenols extraction from dried chokeberry using maceration as traditional technique. Food Chem. 2016;194:135-42.

12. Albuquerque BR, Prieto MA, Barreiro MF, Rodrigues A, Curran TP, Barros L, Ferreira ICFR. Catechin-based extract optimization obtained from Arbutus unedo L. fruits using maceration/microwave/ultrasound extraction techniques. Ind Crops Prod. 2017;95:404-15.

13. Jovanović AA, Đorđević VB, Zdunić GM, Pljevljakušić DS, Šavikin KP, Gođevac DM, Bugarski BM. Optimization of the extraction process of polyphenols from Thymus serpyllum L. herb using maceration, heat- and ultrasound-assisted techniques. Sep Purif Technol. 2017;179:369-80.

14. Jin S, Yang M, Kong Y, Yao X, Wei Z, Zu Y, Fu Y. Microwave-assisted extraction of flavonoids from Cajanus cajan leaves. Zhongcaoyao. 2011:42(11):2235-9.

15. Zhang H, Wang W, Fu ZM, Han CC, Song Y. Study on comparison of extracting fucoxanthin from Undaria pinnatifida with percolation extraction and refluxing methods. Zhongguo Shipin Tianjiaji. 2014;9:91-5.

16. Fu M, Zhang L, Han J, Li J. Optimization of the technology of ethanol extraction for Goupi patch by orthogonal design test. Zhongguo Yaoshi (Wuhan, China). 2008;11(1):75-6.

17. Gao X, Han J, Dai H, Xiang L. Study on optimizing the technological condition of ethanol percolating extraction for Goupi patch. Zhongguo Yaoshi. 2009;12(10):1395-7.

18. Li SL, Lai SF, Song JZ, Qiao CF, Liu X, Zhou Y, Cai H, Cai BC, Xu HX. Decocting-induced chemical transformations and global quality of Du-Shen-Tang, the decoction of ginseng evaluated by UPLC-Q-TOFMS/MS based chemical profiling approach. J Pharm Biomed Anal. 2010;53(4):946-57.

19. Zhang WL, Chen JP, Lam KYC, Zhan JYX, Yao P, Dong TTX, Tsim KWK. Hydrolysis of glycosidic flavonoids during the preparation of Danggui 
Buxue Tang: an outcome of moderate boiling of chinese herbal mixture. Evid Based Complement Altern Med. 2014;2014:608721.

20. Zhang Q, Wang CH, Ma YM, Zhu EY, Wang ZT. UPLC-ESI/MS determination of 17 active constituents in 2 categorized formulas of traditional Chinese medicine, Sanhuang Xiexin Tang and Fuzi Xiexin Tang: application in comparing the differences in decoctions and macerations. Biomed Chromatogr. 2013;27(8):1079-88.

21. Kongkiatpaiboon S, Gritsanapan W. Optimized extraction for high yield of insecticidal didehydrostemofoline alkaloid in Stemona collinsiae root extracts. Ind Crops Prod. 2013;41:371-4.

22. Zhang L. Comparison of extraction effect of active ingredients in traditional Chinese medicine compound preparation with two different method. Heilongjiang Xumu Shouyi. 2013;9:132-3.

23. Wei $Q$, Yang GW, Wang XJ, Hu XX, Chen L. The study on optimization of Soxhlet extraction process for ursolic acid from Cynomorium. Shipin Yanjiu Yu Kaifa. 2013;34(7):85-8.

24. Chin FS, Chong KP, Markus A, Wong NK. Tea polyphenols and alkaloids content using soxhlet and direct extraction methods. World J Agric Sci. 2013;9(3):266-70.

25. Lv GP, Huang WH, Yang FQ, Li J, Li SP. Pressurized liquid extraction and GC-MS analysis for simultaneous determination of seven components in Cinnamomum cassia and the effect of sample preparation. J Sep Sci. 2010;33(15):2341-8

26. Xu J, Zhao WM, Qian ZM, Guan J, Li SP. Fast determination of five components of coumarin, alkaloids and bibenzyls in Dendrobium spp. using pressurized liquid extraction and ultra-performance liquid chromatography. J Sep Sci. 2010;33(11):1580-6.

27. Xu FX, Yuan C, Wan JB, Yan R, Hu H, Li SP, Zhang QW. A novel strategy for rapid quantification of 20(S)-protopanaxatriol and 20(S)-protopanaxadiol saponins in Panax notoginseng, P. ginseng and P. quinquefolium. Nat Prod Res. 2015;29(1):46-52.

28. Vergara-Salinas JR, Bulnes P, Zuniga MC, Perez-Jimenez J, Torres JL, Mateos-Martin ML, Agosin E, Perez-Correa JR. Effect of pressurized hot water extraction on antioxidants from grape pomace before and after enological fermentation. J Agric Food Chem. 2013;61 (28):6929-36.

29. Gizir AM, Turker N, Artuvan E. Pressurized acidified water extraction of black carrot [Daucus carota ssp. sativus var. atrorubens Alef.] anthocyanins. Eur Food Res Technol. 2008;226(3):363-70.

30. Conde-Hernández LA, Espinosa-Victoria JR, Trejo A, Guerrero-Beltrán JÁ. CO2-supercritical extraction, hydrodistillation and steam distillation of essential oil of rosemary (Rosmarinus officinalis). J Food Eng. 2017;200:81-6.

31. Falcão MA, Scopel R, Almeida RN, do Espirito Santo AT, Franceschini G, Garcez JJ, Vargas RMF, Cassel E. Supercritical fluid extraction of vinblastine from Catharanthus roseus. J Supercrit Fluids. 2017;129:9-15.

32. Barba FJ, Zhu Z, Koubaa M, Sant'Ana AS, Orlien V. Green alternative methods for the extraction of antioxidant bioactive compounds from winery wastes and by-products: a review. Trends Food Sci Technol. 2016;49:96-109.

33. Chemat F, Rombaut N, Sicaire AG, Meullemiestre A, Fabiano-Tixier AS, Abert-Vian M. Ultrasound assisted extraction of food and natural products. Mechanisms, techniques, combinations, protocols and applications. A review. Ultrason Sonochem. 2017;34:540-60.

34. Wu QS, Wang CM, Lu JJ, Lin LG, Chen P, Zhang QW. Simultaneous determination of six saponins in Panacis Japonici Rhizoma using quantitative analysis of multi-components with single-marker method. Curr Pharm Anal. 2017;13(3):289-95.

35. Zt Guo, Xq Luo, Jp Liang, Yang Z, Ai X. Comparative study on extraction of febrifugine from traditional Chinese medicine Dichroa febrifuga by reflux method and ultrasonic method. Shizhen Guoyi Guoyao. 2015;26(6):1532-3.

36. Chemat F, Cravotto G. Microwave-assisted extraction for bioactive compounds. Boston: Springer; 2013.

37. Vinatoru M, Mason TJ, Calinescu I. Ultrasonically assisted extraction (UAE) and microwave assisted extraction (MAE) of functional compounds from plant materials. TrAC Trends Anal Chem. 2017:97:159-78

38. Chen H. Optimization of microwave-assisted extraction of resveratrol from Polygonum cuspidatum sieb et Zucc by orthogonal experiment. Nat Prod Indian J. 2013;9(4):138-42.

39. Benmoussa H, Farhat A, Romdhane M, Bouajila J. Enhanced solvent-free microwave extraction of Foeniculum vulgare Mill. essential oil seeds using double walled reactor. Arabian J Chem 2016. (in press https://doi. org/10.1016/j.arabjc.2016.02.010).

40. Xiong W, Chen X, Lv G, Hu D, Zhao J, Li S. Optimization of microwaveassisted extraction of bioactive alkaloids from lotus plumule using response surface methodology. J Pharm Anal. 2016;6(6):382-8.

41. Hou J, He S, Ling M, Li W, Dong R, Pan Y, Zheng Y. A method of extracting ginsenosides from Panax ginseng by pulsed electric field. J Sep Sci. 2010;33(17-18):2707-13.

42. Bouras M, Grimi N, Bals O, Vorobiev E. Impact of pulsed electric fields on polyphenols extraction from Norway spruce bark. Ind Crops Prod. 2016:80:50-8

43. Chen H, Zhou X, Zhang J. Optimization of enzyme assisted extraction of polysaccharides from Astragalus membranaceus. Carbohydr Polym. 2014;111:567-75

44. Liu T, Sui X, Li L, Zhang J, Liang X, Li W, Zhang H, Fu S. Application of ionic liquids based enzyme-assisted extraction of chlorogenic acid from Eucommia ulmoides leaves. Anal Chim Acta. 2016;903:91-9.

45. Strati IF, Gogou E, Oreopoulou V. Enzyme and high pressure assisted extraction of carotenoids from tomato waste. Food Bioprod Process. 2015:94:668-74.

46. Verma SK, Goswami P, Verma RS, Padalia RC, Chauhan A, Singh VR, Darokar MP. Chemical composition and antimicrobial activity of bergamot-mint (Mentha citrata Ehrh.) essential oils isolated from the herbage and aqueous distillate using different methods. Ind Crops Prod. 2016;91:152-60.

47. Yahya A, Yunus RM. Influence of sample preparation and extraction time on chemical composition of steam distillation derived patchouli oil. Proc Eng. 2013;53:1-6.

48. Lim KH, Kam TS. Methyl chanofruticosinate alkaloids from Kopsia arborea. Phytochemistry. 2008;69(2):558-61.

49. Zhang Z, Su Z. Recovery of taxol from the extract of Taxus cuspidato callus cultures with Al2O3 chromatography. J Liq Chromatogr Relat Technol. 2000;23(17):2683-93.

50. Zhang Z, Su Z. Catalysis mechanism to increase taxol from the extract of Taxus cuspidate callus cultures with alumina chromatography. Sep Sci Technol. 2002;37(3):733-43.

51. Gao M, Wang XL, Gu M, Su ZG, Wang Y, Janson JC. Separation of polyphenols using porous polyamide resin and assessment of mechanism of retention. J Sep Sci. 2011;34(15):1853-8.

52. Xs Li, Bq Jiang, Jl Mao. Study on extraction separation and pharmacodynamics of effective components in Kuqingcha. Guangxi Yixue. 2013;35(5):637-8

53. Yang $X$, Wang J, Luo J, Kong L. One-step large-scale preparative isolation of isoquinoline alkaloids from rhizoma coptidis chinensis by polyamide column chromatography and their quantitative structureretention relationship analysis. J Liq Chromatogr Relat Technol. 2012;35(13):1842-52.

54. Li J, Chase HA. Development of adsorptive (non-ionic) macroporous resins and their uses in the purification of pharmacologically-active natural products from plant sources. Nat Prod Rep. 2010;27(10):1493-510.

55. Wan JB, Zhang QW, Ye WC, Wang YT. Quantification and separation of protopanaxatriol and protopanaxadiol type saponins from Panax notoginseng with macroporous resins. Sep Purif Technol. 2008;60(2):198-205.

56. Meng FC, Wu QS, Wang R, Li SP, Lin LG, Zhang QW, Chen P. A novel strategy for quantitative analysis of major ginsenosides in Panacis Japonici Rhizoma with a standardized reference fraction. Molecules. 2017;22(12):2067

57. Wang $X$, Zhao C, Peng X, Tang K. Adsorption mechanism of methoxy modified macroporous crosslinked resin for phenol. Huaxue Xuebao. 2010;68(5):453-6.

58. Liu W, Zhang S, Zu YG, Fu YJ, Ma W, Zhang DY, Kong Y, Li XJ. Preliminary enrichment and separation of genistein and apigenin from extracts of pigeon pea roots by macroporous resins. Bioresour Technol. 2010;101(12):4667-75.

59. Mander LN, Williams CM. Chromatography with silver nitrate: part 2 . Tetrahedron. 2016;72(9):1133-50.

60. Yan Y, Wang X, Liu Y, Xiang J, Wang X, Zhang H, Yao Y, Liu R, Zou $X$, Huang J, et al. Combined urea-thin layer chromatography and silver nitrate-thin layer chromatography for micro separation and 
determination of hard-to-detect branched chain fatty acids in natural lipids. J Chromatogr A. 2015;1425:293-301.

61. Zhang Wm, Zhai Yc, Yang Hj, Zhang Rg, Hao J, Han Jq, Zhang Yl. Silver nitrate-silica gel column chromatography purification linolenic acid in walnut oil. Shipin Gongye Keji. 2015;36(10):229-32.

62. Wang Y, Du Al, Du Aq. Isolation of zingiberene from ginger oleoresin by silver ion coordination column chromatography. Jingxi Huagong 2012;29(7):672-7.

63. Lemos LMS, Oliveira RB, Sampaio BL, Ccana-Ccapatinta GV, Da Costa FB, Martins DTO. Brasiliensic and isobrasiliensic acids: isolation from Calophyllum brasiliense Cambess. and anti-Helicobacter pylori activity. Nat Prod Res. 2016;30(23):2720-5.

64. Li J, Gao R, Zhao D, Huang X, Chen Y, Gan F, Liu H, Yang G. Separation and preparation of xanthochymol and guttiferone $\mathrm{E}$ by high performance liquid chromatography and high speed counter-current chromatography combined with silver nitrate coordination reaction. J Chromatogr A. 2017;1511:143-8.

65. Wan JB, Li P, Yang RL, Zhang QW, Wang YT. Separation and purification of 5 saponins from Panax notoginseng by preparative highperformance liquid chromatography. J Liq Chromatogr Relat Technol. 2013;36(3):406-17.

66. Cai J, Cheng L, Zhao J, Fu Q, Jin Y, Ke Y, Liang X. A novel polyacrylamidebased silica stationary phase for the separation of carbohydrates using alcohols as the weak eluent in hydrophilic interaction liquid chromatography. J Chromatogr A. 2017;1524:153-9.

67. Guzlek H, Wood PL, Janaway L. Performance comparison using the GUESS mixture to evaluate counter-current chromatography instruments. J Chromatogr A. 2009;1216(19):4181-6.

68. Tang Q, Wang Y, Chen M, Zhang Q, Fan C, Huang X, Li Y, Ye W. Application of high-speed counter-current chromatography preparative separation of flavone C-glycosides from Lophatherum gracile. Sep Sci Technol. 2013;48(12):1906-12.

69. Dang YY, Li XC, Zhang QW, Li SP, Wang YT. Preparative isolation and purification of six volatile compounds from essential oil of Curcuma wenyujin using high-performance centrifugal partition chromatography. J Sep Sci. 2010;33(11):1658-64.

70. Zhou YQ, Wang CM, Wang RB, Lin LG, Yin ZQ, Hu H, Yang Q, Zhang QW. Preparative separation of four sesquiterpenoids from Curcuma longa by high-speed counter-current chromatography. Sep Sci Technol. 2017:52(3):497-503

71. Skalicka-Wozniak K, Walasek M, Ludwiczuk A, Glowniak K. Isolation of terpenoids from Pimpinella anisum essential oil by high-performance counter-current chromatography. J Sep Sci. 2013;36(16):2611-4.

72. Li XC, Zhang QW, Yin ZQ, Zhang XQ, Ye WC. Preparative separation of patchouli alcohol from patchouli oil using high performance centrifugal partition chromatography. J Essent Oil Res. 2011;23(6):19-24.

73. Negrão Murakami AN, de Mello Castanho Amboni RD, Prudêncio ES, Amante ER, de Moraes Zanotta L, Maraschin M, Cunha Petrus JC, Teófilo RF. Concentration of phenolic compounds in aqueous mate (llex paraguariensis A. St. Hil) extract through nanofiltration. LWT Food Sci Technol. 2011;44(10):2211-6.

74. Khemakhem I, Gargouri OD, Dhouib A, Ayadi MA, Bouaziz M. Oleuropein rich extract from olive leaves by combining microfiltration, ultrafiltration and nanofiltration. Sep Purif Technol. 2017;172:310-7.

75. Sila A, Bougatef A. Antioxidant peptides from marine by-products: Isolation, identification and application in food systems. A review. J Funct Foods. 2016;21:10-26.

76. Shi L. Bioactivities, isolation and purification methods of polysaccharides from natural products: a review. Int J Biol Macromol. 2016:92:37-48.

77. Schendel RR, Becker A, Tyl CE, Bunzel M. Isolation and characterization of feruloylated arabinoxylan oligosaccharides from the perennial cereal grain intermediate wheat grass (Thinopyrum intermedium). Carbohydr Res. 2015;407:16-25.

78. Pettit GR, Tang YP, Zhang Q, Bourne GT, Arm CA, Leet JE, Knight JC, Pettit RK, Chapuis JC, Doubek DL, et al. Isolation and structures of axistatins 1-3 from the republic of palau marine sponge Agelas axifera hentschel. J Nat Prod. 2013;76(3):420-4.

79. Li J, Cheong K, Zhao J, Hu D, Chen X, Qiao C, Zhang Q, Chen Y, Li S. Preparation of inulin-type fructooligosaccharides using fast protein liquid chromatography coupled with refractive index detection. J Chromatogr A. 2013;1308:52-7.

80. Tan T, Su ZG, Gu M, Xu J, Janson JC. Cross-linked agarose for separation of low molecular weight natural products in hydrophilic interaction liquid chromatography. Biotechnol J. 2010;5(5):505-10.

81. Comeskey DJ, Montefiori M, Edwards PJB, McGhie TK. Isolation and structural identification of the anthocyanin components of red kiwifruit. J Agric Food Chem. 2009;57(5):2035-9.

82. Feng $L$, Zhao F. Separation of polyphenols in tea on weakly acidic cation-exchange gels. Chromatographia. 2010;71(9):775-82.

83. Månsson M, Klejnstrup ML, Phipps RK, Nielsen KF, Frisvad JC, Gotfredsen $\mathrm{CH}$, Larsen TO. Isolation and NMR characterization of fumonisin B2 and a New fumonisin B6 from Aspergillus niger. J Agric Food Chem. 2010;58(2):949-53.

84. Borgarello AV, Mezza GN, Pramparo MC, Gayol MF. Thymol enrichment from oregano essential oil by molecular distillation. Sep Purif Technol. 2015;153:60-6.

85. Xiong Y, Zhao Z, Zhu L, Chen Y, Ji H, Yang D. Removal of three kinds of phthalates from sweet orange oil by molecular distillation. LWT Food Sci Technol. 2013;53(2):487-91.

86. Wang $H$, Yang $F, X i a Z$. Progress in modification of preparative gas chromatography and its applications. Huaxue Tongbao. 2011;74(1):3-9.

87. Yang FQ, Wang HK, Chen H, Chen JD, Xia ZN. Fractionation of volatile constituents from Curcuma rhizome by preparative gas chromatography. J Autom Methods Manage Chem. 2011;2011:6. https://doi. org/10.1155/2011/942467:942467.

88. Zuo HL, Yang FQ, Zhang XM, Xia ZN. Separation of cis- and trans-asarone from Acorus tatarinowii by preparative gas chromatography. J Anal Methods Chem. 2012;2012:5. https://doi.org/10.1155/2012/402081.

89. OzekT, Demirci F. Isolation of natural products by preparative gas chromatography. Methods Mol Biol. 2012;864:275-300.

90. Speybrouck D, Lipka E. Preparative supercritical fluid chromatography: a powerful tool for chiral separations. J Chromatogr A. 2016;1467:33-55.

91. Hartmann A, Ganzera M. Supercritical fluid chromatography—-theoretical background and applications on natural products. Planta Med. 2015;81(17):1570-81.

92. Gibitz Eisath N, Sturm S, Stuppner H. Supercritical fluid chromatography in natural product analysis_-an update. Planta Med. 2017; In press.

93. Zhao Y, McCauley J, Pang X, Kang L, Yu H, Zhang J, Xiong C, Chen R, Ma B. Analytical and semipreparative separation of 25 (R/S)-spirostanol saponin diastereomers using supercritical fluid chromatography. J Sep Sci. 2013;36(19):3270-6.

94. Yang W, Zhang Y, Pan H, Yao C, Hou J, Yao S, Cai L, Feng R, Wu W, Guo D. Supercritical fluid chromatography for separation and preparation of tautomeric 7-epimeric spiro oxindole alkaloids from Uncaria macrophylla. J Pharm Biomed Anal. 2017;134:352-60.

95. Nie L, Dai Z, Ma S. Improved chiral separation of (R, S)-goitrin by SFC: an application in traditional Chinese medicine. J Anal Methods Chem. 2016;2016:5. https://doi.org/10.1155/2016/5782942.

96. Ji W, Xie H, Zhou J, Wang X, Ma X, Huang L. Water-compatible molecularly imprinted polymers for selective solid phase extraction of dencichine from the aqueous extract of Panax notoginseng. J Chromatogr B. 2016;1008:225-33.

97. Ma X, Meng Z, Qiu L, Chen J, Guo Y, Yi D, Ji T, Jia H, Xue M. Solanesol extraction from tobacco leaves by Flash chromatography based on molecularly imprinted polymers. J Chromatogr B. 2016;1020:1-5.

98. You Q, Zhang Y, Zhang Q, Guo J, Huang W, Shi S, Chen X. High-capacity thermo-responsive magnetic molecularly imprinted polymers for selective extraction of curcuminoids. J Chromatogr A. 2014;1354:1-8.

99. Okinyo-Owiti DP, Burnett PGG, Reaney MJT. Simulated moving bed purification of flaxseed oil orbitides: unprecedented separation of cyclolinopeptides C and E. J Chromatogr B. 2014;965:231-7.

100. Kang SH, Kim JH, Mun S. Optimal design of a tandem simulated moving bed process for separation of paclitaxel, 13-dehydroxybaccatin III, and 10-deacetylpaclitaxel. Process Biochem. 2010;45(9):1468-76.

101. Mun S. Enhanced performance of a tandem simulated moving bed process for separation of paclitaxel, 13-dehydroxybaccatin III, and 10-deacetylpaclitaxel by making a difference between the adsorbent particle sizes of the two subordinate simulated moving bed units. Process Biochem. 2011;46(6):1329-34. 
102. Liang MT, Liang RC, Yu SQ, Yan RA. Separation of resveratrol and emodin by supercritical fluid-simulated moving bed chromatography. J Chromatogr Sep Tech. 2013;4(3):1000175.

103. Sciarrone D, Panto S, Rotondo A, Tedone L, Tranchida PQ, Dugo P, Mondello L. Rapid collection and identification of a novel component from Clausena lansium Skeels leaves by means of three-dimensional preparative gas chromatography and nuclear magnetic resonance/ infrared/mass spectrometric analysis. Anal Chim Acta. 2013;785:119-25.

104. Cui Y, Shen N, Yuan X, Dang J, Shao Y, Mei L, Tao Y, Wang Q, Liu Z. Twodimensional chromatography based on on-line HPLC-DPPH bioactivityguided assay for the preparative isolation of analogue antioxidant compound from Arenaria kansuensis. J Chromatogr B. 2017;1046:81-6.
105. Sciarrone D, Panto S, Donato P, Mondello L. Improving the productivity of a multidimensional chromatographic preparative system by collecting pure chemicals after each of three chromatographic dimensions. J Chromatogr A. 2016;1475:80-5.

106. Panto S, Sciarrone D, Maimone M, Ragonese C, Giofre S, Donato P, Farnetti S, Mondello L. Performance evaluation of a versatile multidimensional chromatographic preparative system based on three-dimensional gas chromatography and liquid chromatographytwo-dimensional gas chromatography for the collection of volatile constituents. J Chromatogr A. 2015;1417:96-103.
Ready to submit your research? Choose BMC and benefit from:

- fast, convenient online submission

- thorough peer review by experienced researchers in your field

- rapid publication on acceptance

- support for research data, including large and complex data types

- gold Open Access which fosters wider collaboration and increased citations

- maximum visibility for your research: over $100 \mathrm{M}$ website views per year

At BMC, research is always in progress.

Learn more biomedcentral.com/submissions 